\title{
Granitoides arqueanos da região de Água Azul do Norte, Província Carajás, sudeste do estado do Pará: petrografia, geoquímica e geocronologia Archean granitoids of the Água Azul do Norte region, Carajás Province, southeast of Pará State: petrography, geochemistry and geochronology
}

\author{
Max de Jesus Pereira dos Santos', Claudio Nery Lamarão', Paulo Henrique Araújo Lima', \\ Marco Antônio Galarza!', Jardel Carlos Lima Mesquital \\ 'Universidade Federal do Pará. Belém, Pará, Brasil
}

Resumo: Granitoides arqueanos aflorantes entre as cidades de Água Azul do Norte e Ourilândia do Norte, porção NW do Terreno Granito-Greenstone de Rio Maria, Província Carajás, foram agrupados em associações granodiorítica e trondhjemítica. As rochas granodioríticas são constituídas por: 1) anfibólio-biotita-granodioritos fortemente saussuritizados, com idade de cristalização de $2875 \pm 2 \mathrm{Ma}$, conteúdo de máficos entre 16 e 21\%, teores elevados de $\mathrm{Ni}, \mathrm{Cr}$ e $\mathrm{Mg}$, padrão contínuo de fracionamento dos elementos terras raras e anomalias negativas de Eu desprezíveis, assemelhando-se petrográfica, geoquímica e geocronologicamente às rochas da Suíte Sanukitoide Rio Maria; 2) biotita-granodioritos menos alterados, com idade de cristalização de $2884 \pm 3$ Ma e total de máficos variando de 8 a 15\%, comparativamente mais enriquecidos em elementos terras raras e com pronunciadas anomalias negativas de Eu, diferindo em termos petrográficos e geoquímicos das rochas anteriores; 3) leucogranodioritos-granitos de coloração esbranquiçada a rosada, contendo fenocristais de plagioclásio e álcali feldspato, correlacionados às rochas da Suíte Guarantã. As rochas trondhjemíticas são representadas por biotita-epidoto-trondhjemitos, tendo biotita e epidoto como principais fases magmáticas, altas razões La/Yb, Sr/Y e Nb/Ta e fortes similaridades com as rochas do Trondhjemito Mogno.

Palavras-chave: Província Carajás. Granodioritos. Trondhjemitos. Petrografia. Geoquímica.

\begin{abstract}
Archean granitoids outcropping between Água Azul do Norte and Ourilândia do Norte cities, NW portion of the Rio Maria Granite-Greenstone Terrain, Carajás Province, were grouped into granodioritic and trondhjemitic associations. The granodioritic rocks are constituted of: 1) amphibole-biotite granodiorite strongly saussuritized, with crystallization age of $2875 \pm 2 \mathrm{Ma}$, mafic contents between 16 and 21\%, high contents of $\mathrm{Ni}, \mathrm{Cr}$ and $\mathrm{Mg}$, continuum pattern of fractionating rare earth elements and absence of significant Eu negative anomaly, resembling petrographic, geochemical and geochronologically the rocks of the Rio Maria Sanukitoid Suite; 2) less altered biotite granodiorite with crystallization age of $2884 \pm 3 \mathrm{Ma}$ and total mafic ranging from 8-15\%, comparatively more enriched in rare earth elements with pronounced negative Eu anomalies, differing petrographic and geochemically from previous rocks; 3 ) leucogranodiorites - whitish to pinkish granites, containing phenocrysts of plagioclase and alkali feldspar, correlated to rocks of the Guarantã Suite. Trondhjemites are represented by biotite-epidote trondhjemites, with biotite and epidote as the main magmatic phases, high La/Yb, $\mathrm{Sr} / \mathrm{Y}$ and $\mathrm{Nb} / \mathrm{Ta}$ ratios and strong similarities with the rocks of the Mogno Trondhjemite.
\end{abstract}

Keywords: Carajás Province. Granodiorites. Trondhjemites. Petrography. Geochemistry.

SANTOS, M. J. P., C. N. LAMARÃO, P. H. A. LIMA, M. A. GALARZA \& J. C. L. MESQUITA, 2013. Granitoides arqueanos da região de Água Azul do Norte, Província Carajás, sudeste do estado do Pará: petrografia, geoquímica e geocronologia. Boletim do Museu Paraense Emílio Goeldi. Ciências Naturais 8(3): 325-354.

Autor para correspondência: Claudio Nery Lamarão. Universidade Federal do Pará. Instituto de Geociências. Av. Augusto Corrêa, 1 - Guamá. Belém, PA, Brasil. CEP66075-110 (lamarao@ufpa.br).

Recebido em 05/07/2013

Aprovado em 10/12/2013

Responsabilidade editorial: Fernando Jacques Althoff

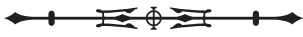




\section{INTRODUÇÃO}

Associações tonalito-trondhjemito-granodiorito (TTG) constituem em torno de 50\% das rochas expostas nos crátons arqueanos (Condie, 1993). Essas associações são os componentes félsicos mais antigos de crátons, formam o embasamento gnáissico da crosta continental arqueana preservada e também podem formar plútons sin a póstectônicos (Barker \& Arth, 1976; Barker, 1979; Martin, 1987, 1994; Bickle et al., 1993; Kröner et al., 1996; Martin et al., 1997; Althoff et al., 2000; Souza et al., 2001; Champion \& Smithies, 2007; Moyen et al., 2007).

O Cráton Amazônico é uma das principais unidades tectônicas da Plataforma Sul-Americana, constituído pelos escudos das Guianas e Brasil Central, separados pela expressiva faixa sedimentar das bacias do Amazonas e Solimões (Vasquez et al., 2008). O Cráton Amazônico representa uma grande placa litosférica continental, composta por várias províncias crustais de idades arqueana a mesoproterozoica, estabilizada em torno de 1,0 Ga, tendo-se comportado como uma placa estável no Neoproterozoico, durante o desenvolvimento das faixas orogênicas marginais brasilianas (Brito Neves \& Cordani, 1991). Algumas províncias podem incluir núcleos antigos mais preservados e porções com rochas metamórficas mais jovens, formadas em eventos posteriores (Tassinari \& Macambira, 1999). A evolução do Cráton Amazônico é resultante de sucessivos episódios de acresção crustal durante o paleoproterozoico e o mesoproterozoico, em volta de um núcleo mais antigo, estabilizado no final do Arqueano (Tassinari \& Macambira, 2004). No sudeste do Cráton Amazônico, está localizado o Terreno Granito-Greenstone de Rio Maria (TGGRM), nos domínios geocronológicos da Província Amazônia Central (Tassinari \& Macambira, 1999, 2004) ou Província Carajás (Santos et al., 2000; Santos, 2003; Figura 1).

A elaboração de um quadro geológico regional mais completo para esse terreno concretizou-se em decorrência de mapeamento geológico executado desde a década de 1980 pela empresa DOCEGEO e por mapeamentos geológicos de semidetalhe, estudos petrográficos, geoquímicos, estruturais, de suscetibilidade magnética e geocronológicos, realizados por pesquisadores da Universidade Federal do Pará (Leite et al., 1999, 2004; D. C. Oliveira et al., 2009, 2010; M. A. Oliveira et al., 2006, 2009; Guimarães et al., 2010; Almeida et al., 2010, 2011, 2013; Paiva Júnior et al., 2011).

Este estudo tem como objetivo principal realizar e discutir a petrografia, geoquímica e geocronologia de granitoides arqueanos que ocorrem na região de Água Azul do Norte - Ourilândia do Norte, sudeste do estado do Pará, comparando-os com rochas correlatas, de modo a contribuir para um melhor posicionamento estratigráfico e entendimento da evolução geológica do TGGRM.

\section{LOCALIZAÇÃO E ACESSO}

A área de trabalho (Figura 2) localiza-se entre os municípios de Água Azul do Norte e Ourilândia do Norte, domínios da Província Carajás. $\bigcirc$ acesso a ela pode ser feito, a partir de Belém, pela rodovia federal BR-010 até o município de Dom Eliseu, seguindo pela PA-222 até o município de Água Azul do Norte, com um total de 982 km desde seu ponto de partida.

\section{SÍNTESE DOS GRANITOIDES DO TGGRM}

O TGGRM (Figura 3) está situado na borda sudeste do Cráton Amazônico, dentro dos domínios da Província Amazônia Central (Tassinari \& Macambira, 1999, 2004). Ele é formado por greenstone-belts e granitoides arqueanos. Os greenstone-belts, com idades entre 2,97-2,90 Ga, representam as rochas mais antigas e foram agrupados no Supergrupo Andorinhas (Souza et al., 2001). Os granitoides formam típicas suítes TTG arqueanas com idades entre 2,982,93 Ga, sendo representadas pelo Tonalito Arco Verde, Trondhjemito Mogno, Complexo Tonalítico Caracol e Tonalito Mariazinha (Pimentel \& Machado, 1994; Macambira \& Lafon, 1995; Althoff et al., 2000; Leite et al., 2004; Dall'Agnol et al., 2006; M. A. Oliveira et al., 2006, 2009; Guimarães et al., 2010; Almeida et al., 2011), além de uma série de granitoides mais jovens, com idades entre 2,87-2,86 


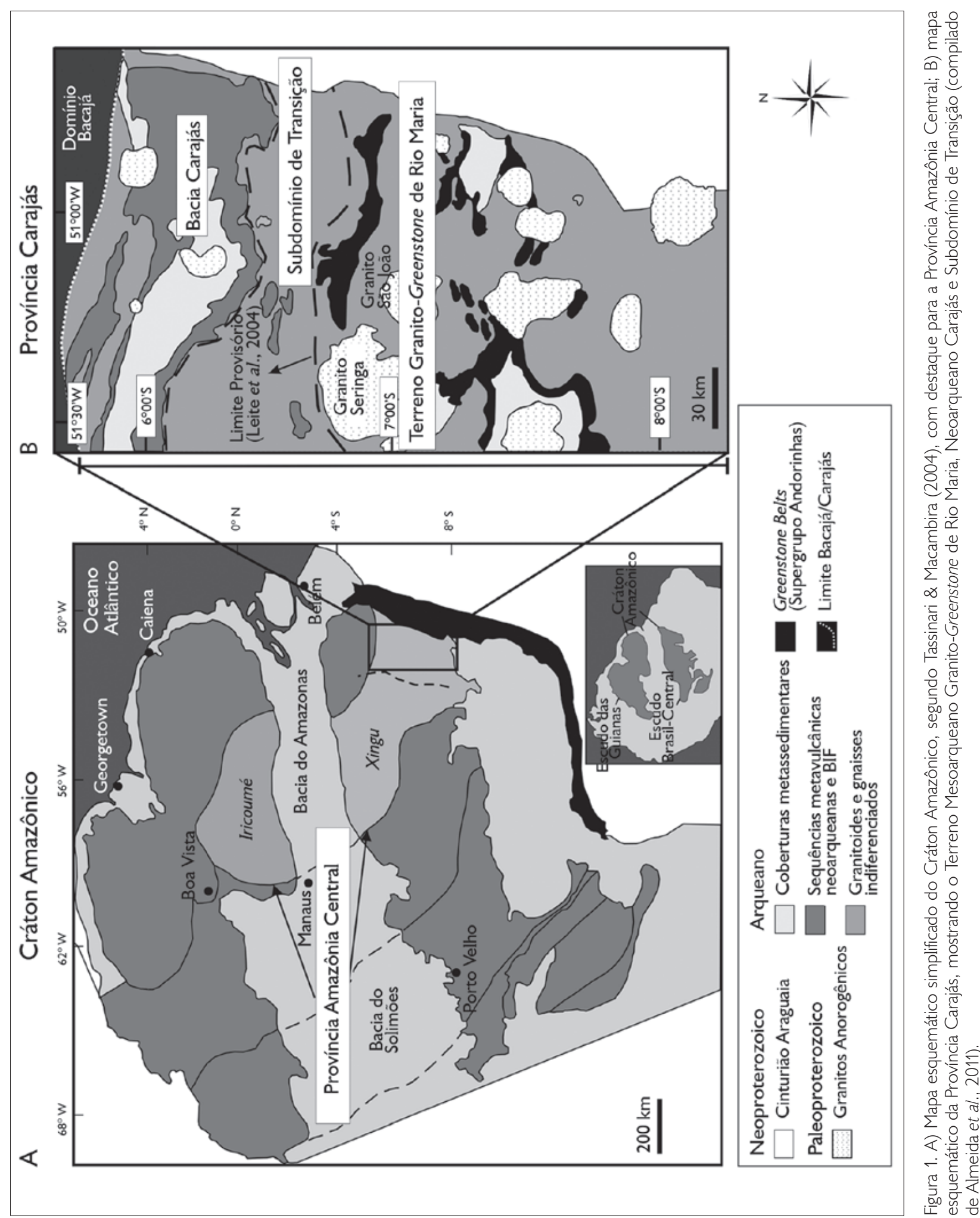


Ga, que seccionam as rochas TTG. Fazem parte destes últimos (Tabela 1): 1) Suíte Sanukitoide Rio Maria, composta dominantemente por granodioritos com alto $\mathrm{Mg}, \mathrm{Cr}$ e Ni (M. A. Oliveira et al., 2009); 2) Trondhjemito Água Fria (2,86 $\mathrm{Ga})$, exposto na área de Xinguara e intrusivo no Complexo Tonalítico Caracol; 3) leucomonzogranitos potássicos, representados pelos plútons Xinguara e Mata Surrão, com idades entre 2,87-2,86 Ga (Leite et al., 2004; Almeida et al., 2011); e 4) leucogranodioritos-granitos Trairão, Azulona e Guarantã, com idade em torno de 2,87 Ga e afinidade cálcio-alcalina, enriquecidos em Ba e Sr, sendo incluídos na Suíte Guarantã (Almeida et al., 2010, 2013).

Em torno de 1,88 Ga, durante o paleoproterozoico, a região do TGGRM foi palco de intenso magmatismo granítico anorogênico (Dall'Agnol et al., 1997, 2005), representado pela Suíte Jamon e por diques félsicos a máficos, localizadamente compostos, que seccionam as unidades arqueanas.

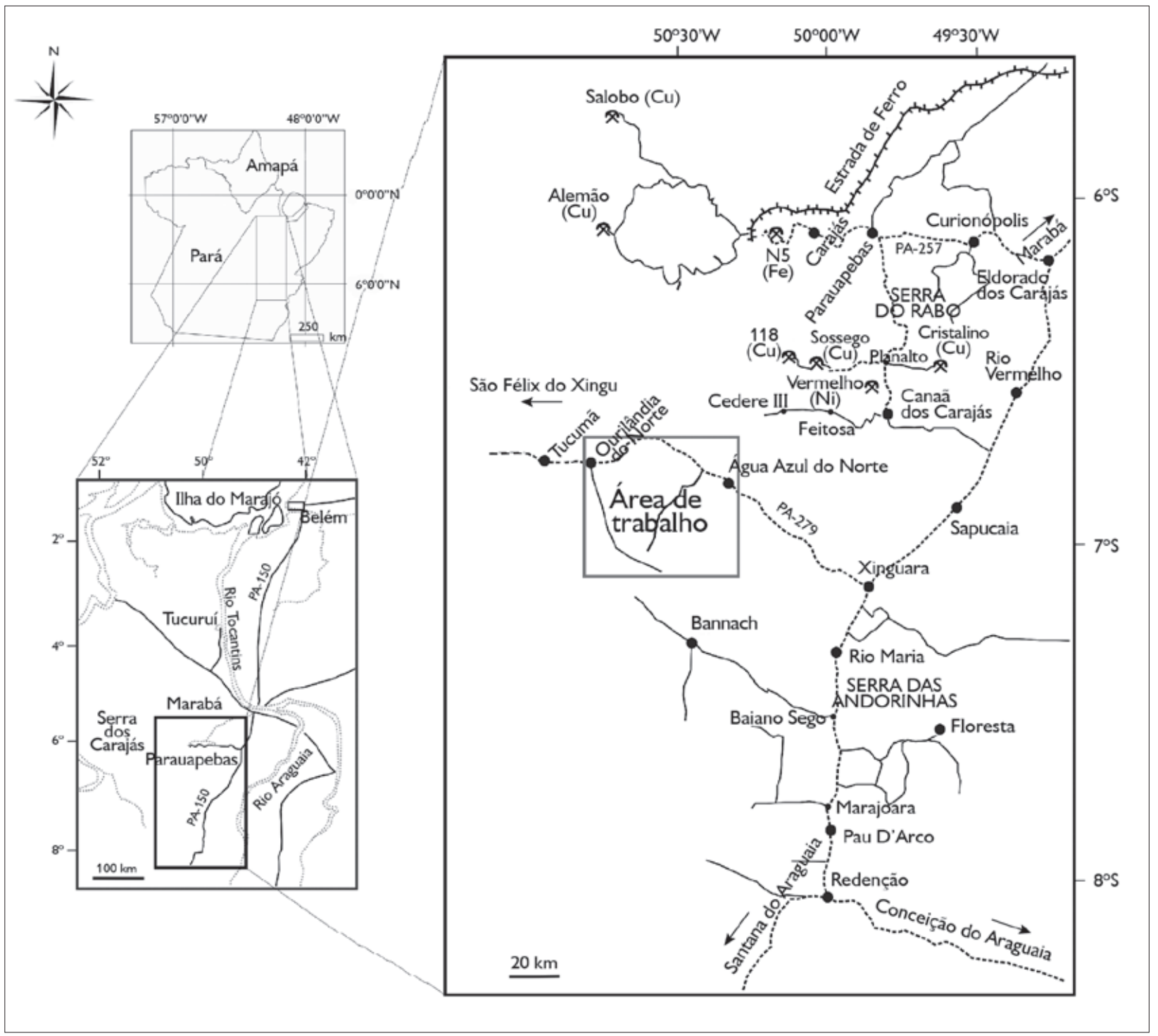

Figura 2. Mapa de localização e vias de acesso à área de estudo. Modificado de Guimarães et al., 2010.

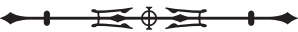



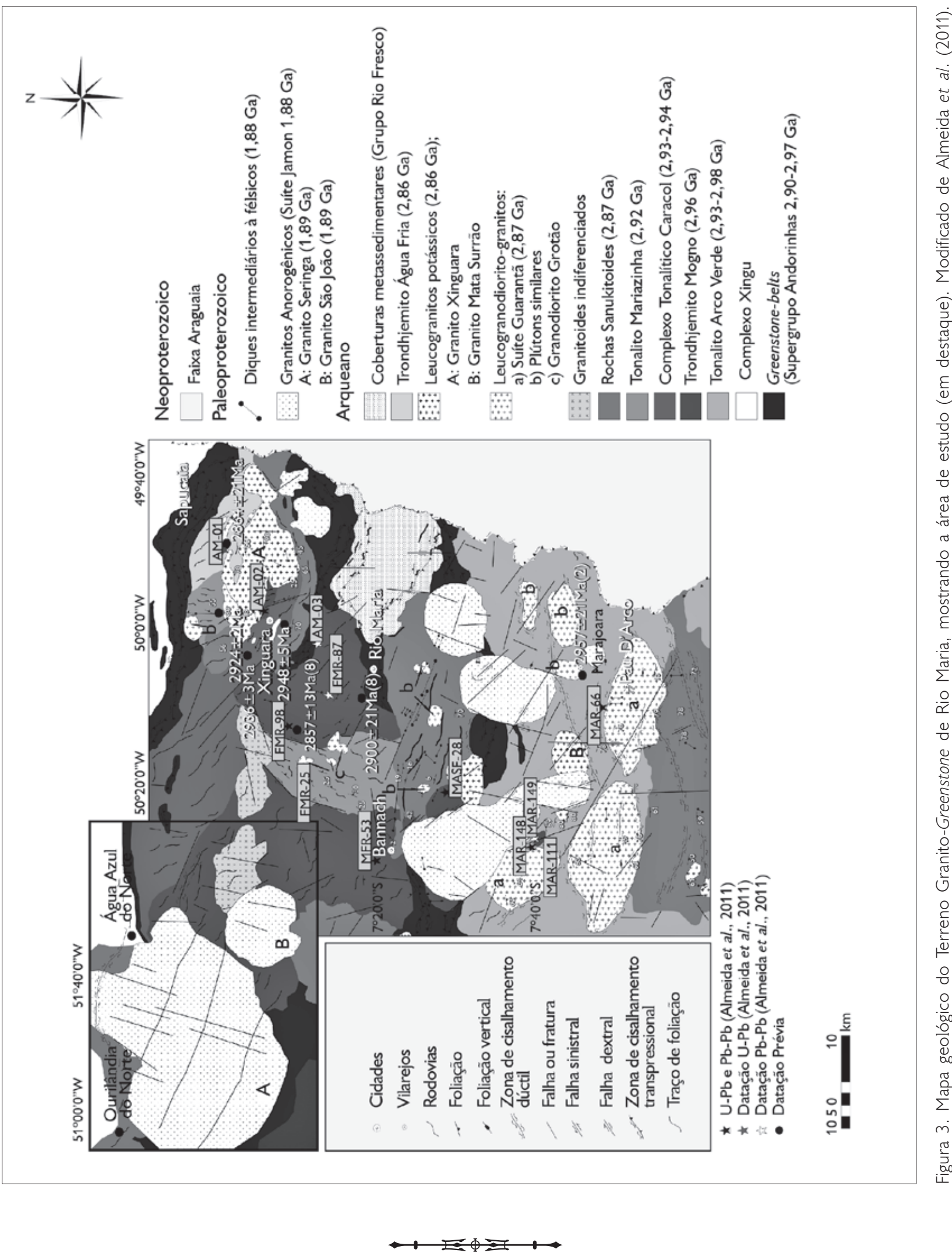
Tabela 1. Dados geocronológicos de unidades pertencentes ao TGGRM, Cráton Amazônico. Modificado de Almeida et al. (2011). Fontes: (1) Pimentel \& Machado (1994), (2) Macambira \& Lancelot (1996), (3) Rolando \& Macambira (2003), (4) Vasquez et al. (2008), (5) Leite et al. (2004), (6) Dall'Agnol et al. (1999), (7) Macambira et al. (2000), (8) Althoff et al. (2000), (9) Almeida et al. (2008), (10) Lafon et al. (1994), (11) Almeida et al. (2011).

(Continua)

\begin{tabular}{|c|c|c|c|c|}
\hline Unidades estratigráficas & Rocha & Método & Material analisado & Idade (Ma) \\
\hline \multicolumn{5}{|c|}{ Leucogranitos potássicos } \\
\hline Granito Xinguara & Leucogranito & $\mathrm{Pb}-\mathrm{Pb}$ & Zircão & $2865 \pm 1(5)$ \\
\hline \multirow{3}{*}{ Granito Mata Surrão } & Leucogranito & $\mathrm{Pb}-\mathrm{Pb}$ & Rocha Total & $2872 \pm 10(10)$ \\
\hline & Leucogranito & $\mathrm{Pb}-\mathrm{Pb}$ & Zircão & $2875 \pm 11(3)$ \\
\hline & Leucogranito & $\mathrm{Pb}-\mathrm{Pb}$ & Zircão & $2881 \pm 2(3)$ \\
\hline \multicolumn{5}{|c|}{ Leucogranodiorito-granito } \\
\hline \multirow{5}{*}{ Suíte Guarantã } & Granodiorito & $\mathrm{Pb}-\mathrm{Pb}$ & Zircão & $2868 \pm 5(9)$ \\
\hline & Leucogranito & $\mathrm{Pb}-\mathrm{Pb}$ & Zircão & $2870 \pm 5(8)$ \\
\hline & Granito Guarantã & $\mathrm{Pb}-\mathrm{Pb}$ & Zircão & $2864 \pm 8(11)$ \\
\hline & Granito Guarantã & $\mathrm{Pb}-\mathrm{Pb}$ & Zircão & $2875 \pm 8(11)$ \\
\hline & Granodiorito Guarantã & $\mathrm{Pb}-\mathrm{Pb}$ & Zircão & $2872 \pm 7(11)$ \\
\hline \multicolumn{5}{|c|}{ Séries TTG Jovens } \\
\hline \multirow{2}{*}{ Trondhjemito Água Fria } & Trondhjemito & $\mathrm{Pb}-\mathrm{Pb}$ & Zircão & $2864 \pm 21(5)$ \\
\hline & Trondhjemito & $\cup-\mathrm{Pb}$ & & $2854 \pm 17(11)$ \\
\hline \multicolumn{5}{|c|}{ Suíte Sanukitoide Rio Maria } \\
\hline \multirow{5}{*}{$\begin{array}{l}\text { Granodiorito Rio Maria } \\
\text { e rochas relacionadas }\end{array}$} & Granodiorito & $\cup-\mathrm{Pb}$ & Zircão & $2874+9 /-10(2)$ \\
\hline & Granodiorito & $\cup-\mathrm{Pb}$ & Zircão, Titanita & $2872 \pm 5(1)$ \\
\hline & Quartzo-diorito & $\mathrm{Pb}-\mathrm{Pb}$ & Zircão & $2878 \pm 4(6)$ \\
\hline & Diorito & $\mathrm{Pb}-\mathrm{Pb}$ & Zircão & $2880 \pm 4(3)$ \\
\hline & Granodiorito & $\mathrm{Pb}-\mathrm{Pb}$ & Zircão & $2877 \pm 6(3)$ \\
\hline Tonalito Parazônia & Tonalito & U-Pb & Titanita & $2858(1)$ \\
\hline \multicolumn{5}{|c|}{ Séries TTG Antigas } \\
\hline \multirow{3}{*}{ Complexo Tonalítico Caracol } & Tonalito & $\mathrm{Pb}-\mathrm{Pb}$ & Zircão & $2948 \pm 5(5)$ \\
\hline & Tonalito & $\mathrm{Pb}-\mathrm{Pb}$ & Zircão & $2936 \pm 3(5)$ \\
\hline & Tonalito & $\mathrm{Pb}-\mathrm{Pb}$ & Zircão & $2924 \pm 2(5)$ \\
\hline \multicolumn{5}{|c|}{ Séries TTG Antigas } \\
\hline \multirow{6}{*}{ Trondhjemito Mogno } & Trondhjemito & $\mathrm{U}-\mathrm{Pb}$ & Titanita & $2871 \pm 7(1)$ \\
\hline & Trondhjemito & $\mathrm{Pb}-\mathrm{Pb}$ & Zircão & $2857 \pm 13(7)$ \\
\hline & Trondhjemito & $\mathrm{Pb}-\mathrm{Pb}$ & Zircão & $2900 \pm 21(7)$ \\
\hline & Trondhjemito & $\mathrm{Pb}-\mathrm{Pb}$ & Zircão & $2962 \pm 8(11)$ \\
\hline & Trondhjemito & $\mathrm{Pb}-\mathrm{Pb}$ & Zircão & $2968 \pm 2(11)$ \\
\hline & Trondhjemito & $\mathrm{Pb}-\mathrm{Pb}$ & Zircão & $2959 \pm 2(11)$ \\
\hline
\end{tabular}


Tabela 1.

(Conclusão)

\begin{tabular}{|c|c|c|c|c|}
\hline Unidades estratigráficas & Rocha & Método & Material analisado & Idade (Ma) \\
\hline \multirow{6}{*}{ Tonalito Arco Verde } & Tonalito & $\mathrm{Pb}-\mathrm{Pb}$ & Zircão & $2964 \pm 4(4)$ \\
\hline & Tonalito & $\mathrm{Pb}-\mathrm{Pb}$ & Zircão & $2948 \pm 7(3)$ \\
\hline & Tonalito & $\mathrm{Pb}-\mathrm{Pb}$ & Zircão & $2981 \pm 8(3)$ \\
\hline & Tonalito & $\mathrm{Pb}-\mathrm{Pb}$ & Zircão & $2988 \pm 5(3)$ \\
\hline & Tonalito & $\mathrm{Pb}-\mathrm{Pb}$ & Zircão & $2952 \pm 2(11)$ \\
\hline & Tonalito & U-Pb & Zircão & $2973 \pm 11(11)$ \\
\hline \multicolumn{5}{|c|}{ Greenstone belts } \\
\hline \multirow{2}{*}{ Supergrupo Andorinhas } & Metavulcânica félsica & U-Pb & Zircão & $2904+29 /-22(2)$ \\
\hline & Metagrauvaca & U-Pb & Zircão & $2971 \pm 18(2)$ \\
\hline
\end{tabular}

\section{GEOLOGIA DAS ROCHAS GRANITOIDES ESTUDADAS}

Na região de Água Azul do Norte - Ourilândia do Norte, dominam rochas granitoides arqueanas, que são cortadas pelos granitos paleoproterozoicos Seringa e São João e por diversos diques máficos a félsicos. As rochas arqueanas, objeto deste trabalho, foram divididas em quatro grupos principais (Figura 4):

- Trondhjemitos: ocorrem na porção ENE da área de estudo. São limitados a norte por greenstonebelts do Grupo Tucumã; a oeste, pelo granito Seringa; a leste e a sul, por leucomonzogranitos a leucogranodioritos. Afloram sob a forma de lajeiros e apresentam comportamento anisotrópico, evidenciado pela presença de foliação com padrão dominante NE-SW e bandamento composicional. Por vezes ocorrem fraturados e preenchidos por veios de composição quartzo-feldspática, concordantes ou discordantes da foliação.

- Anfibólio-biotita-granodioritos: estão presentes na porção NWN da área, nas proximidades da cidade de Ourilândia do Norte. Limitam-se a norte pelas rochas do Complexo Xingu, a sudeste pelo granito Seringa e a sudoeste pelas rochas metassedimentares do Grupo Tucumã. Apresentam-se leve a fortemente estruturados, com seus minerais máficos e félsicos definindo bandamentos composicionais. As foliações mostram um trend principal de direção NW-SE a WNW-ESE concordante com a foliação regional, tornando-se mais penetrativa nas proximidades do batólito Seringa. A presença de enclaves máficos centimétricos a métricos é o melhor marcador da foliação. As rochas dessa unidade geralmente ocorrem sob a forma de morrotes e blocos isolados. Outra característica marcante é a sua coloração cinza-esverdeada, em decorrência de processo de saussuritização dos plagioclásios.

- Biotita-granodioritos: estão presentes no domínio NE da área, onde são cortados, a sul, pelo granito Seringa, a oeste, pelas rochas sanukitoides e limitada, a sudeste, pelas rochas metavulcânicas do Grupo Tucumã. São marcados principalmente por estruturação evidenciada por lamelas micáceas, definindo planos de foliação. Planos de cisalhamentos cortam essas rochas segundo direção $20^{\circ} \mathrm{Az}$. Estruturas presentes nessas rochas, como bandamento composicional, são de origem metamórfica, evidenciadas pela presença de texturas miloníticas. Apresentam coloração cinza e texturalmente variações porfirítica e hipidiomórfica média a grossa. Destacam-se por possuir a biotita como única fase varietal.

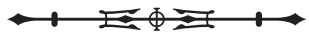


- Leucogranodioritos-granitos: ocorrem nas porções NNE e W do granito São João (Figura 4), sendo limitados a norte pelas metavulcânicas do Grupo Tucumã. São cortados por diques do granito Seringa e de rochas trondhjemíticas. São rochas texturalmente heterogêneas, variando de granodioríticas a monzograníticas. Sua principal característica é a presença de fenocristais de plagioclásio e álcali feldspato. Macroscopicamente não apresentam sinais de deformação evidente. No entanto, na região de contato com o granito São João, microscopicamente percebe-se que seus minerais félsicos se dispõem formando mosaicos.

\section{PETROGRAFIA}

\section{COMPOSIÇÕES MODAIS E CLASSIFICAÇÃO}

Foram realizadas análises modais em 32 amostras (Tabela 2) e os resultados, lançados nos diagramas Q-A-P e Q-(A+P)-M' (Streckeisen, 1976; Figura 5), sendo distinguidas quatro unidades litológicas: biotitaepidoto-trondhjemito (BEpTrd), anfibólio-biotitagranodiorito (ABGrd), biotita-granodiorito (BGrd) e leucogranodioritos-granitos (LGrdG).

As rochas trondhjemíticas (BEpTrd) contêm média de $56,6 \%$ de plagioclásio, $35 \%$ de quartzo e $<3,5 \%$ de álcali feldspato. A biotita, variando de 2,7 a $8,9 \%$ modal, e o epidoto magmático são as principais fases máficas, sendo notável a ausência de hornblenda. As fases acessórias mais comuns são zircão e opacos, com rara apatita, titanita e allanita. As rochas granodioríticas dividem-se em dois grupos, com base nas fases máficas presentes. O primeiro é representado pelos $A B G r d$, com média de $37,6 \%$ de plagioclásio, $24 \%$ de quartzo e $16 \%$ de álcali feldspato, e conteúdo de minerais máficos entre 15,8 e 20,8\%. O segundo corresponde aos BGrd, com conteúdos médios de $40 \%$ de plagioclásio, 30\% de quartzo, 17,1\% de álcali feldspato e total de máficos variando de 8,5 a $14,7 \%$. Ambas as unidades possuem zircão, allanita,

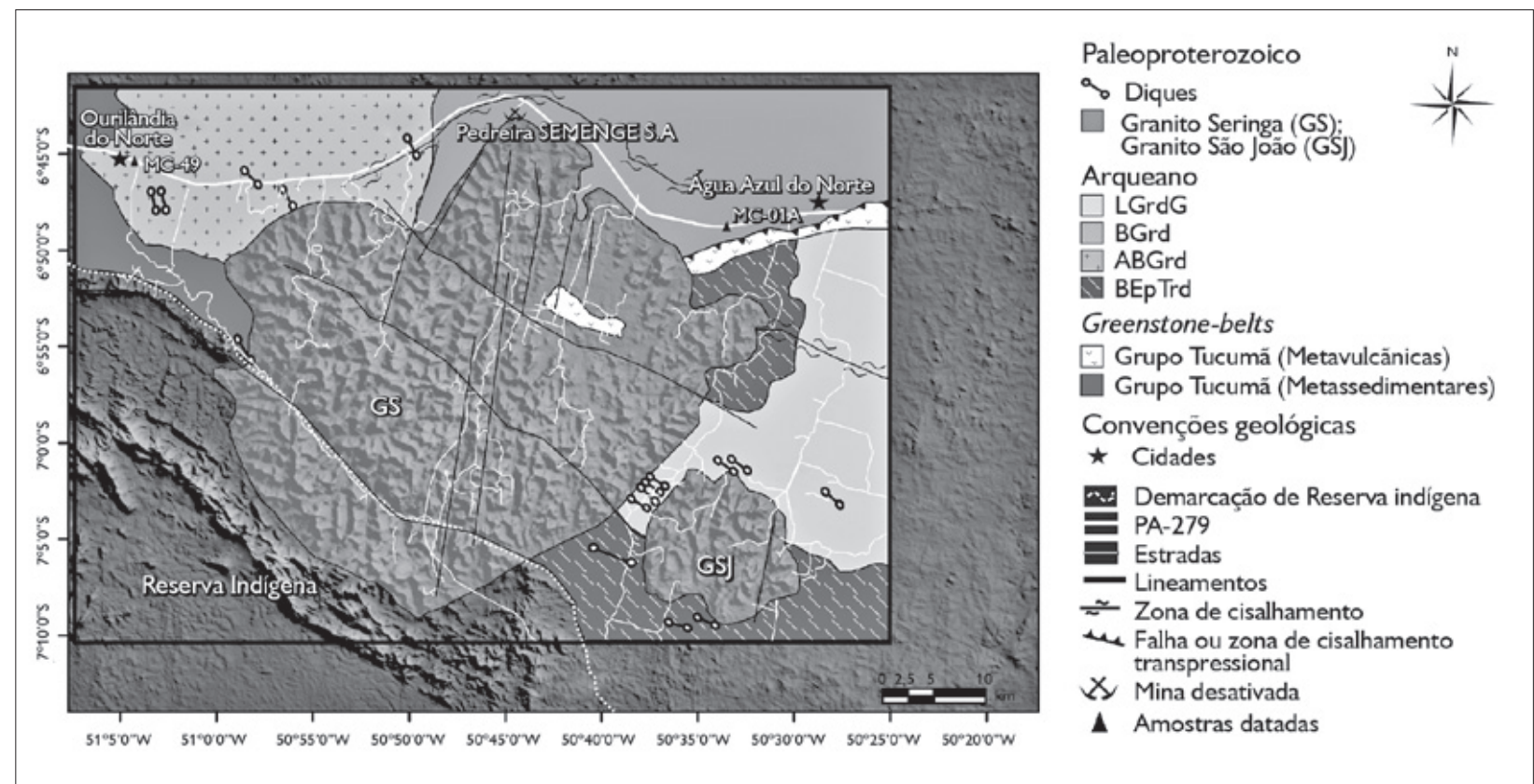

Figura 4. Mapa geológico da área estudada. Modificado dos Trabalhos de Conclusão de Curso em Geologia de M. J. P. Santos (defendido em 2011) e J. C. L. Mesquita (defendido em 2011), Belém. Legendas: BEpTrd = biotita-epidoto-trondhjemito; ABGrd = anfibólio-biotitagranodiorito; BGrd = biotita-granodiorito; LGrdG = leucogranodioritos-granitos.

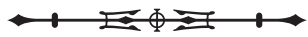




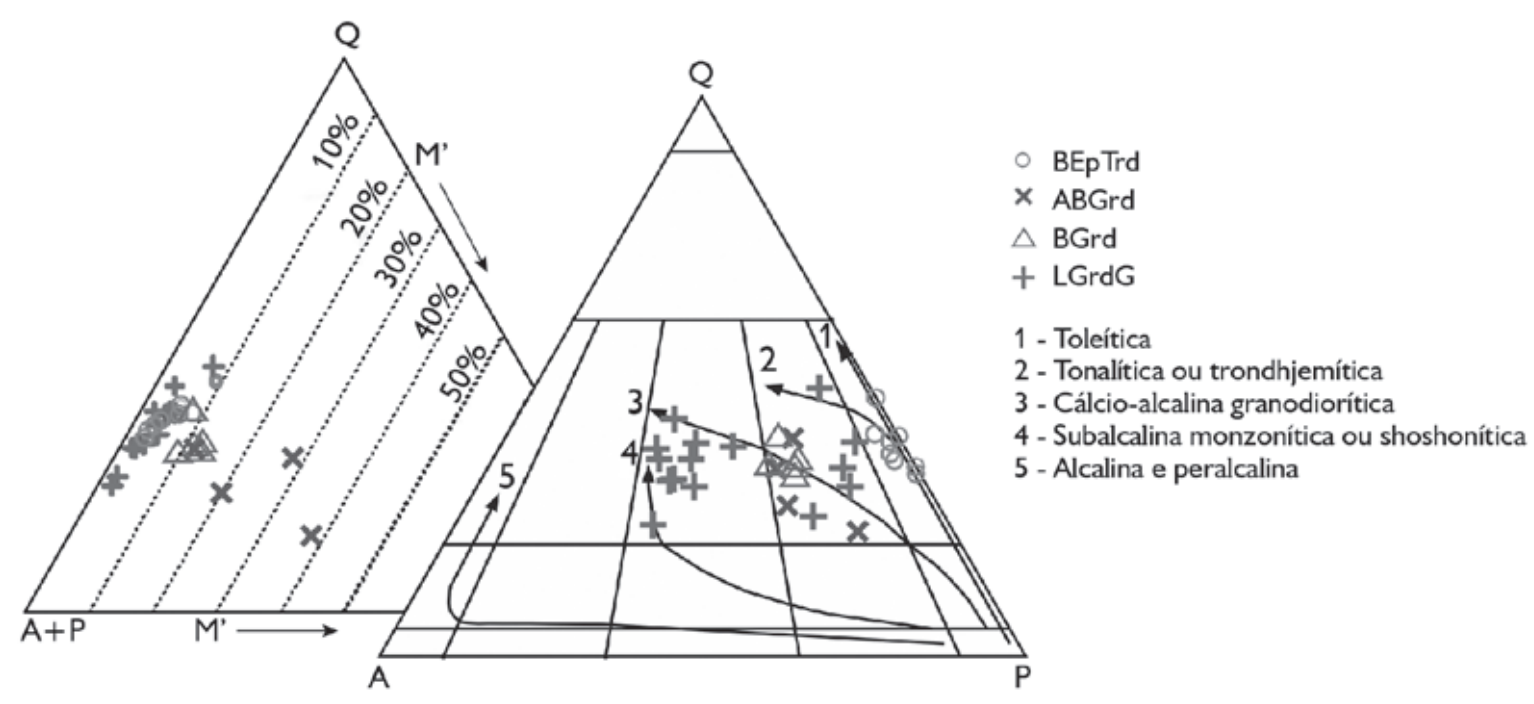

Figura 5. Diagramas modais Q-A-P e Q-(A+P)-M' (Streckeisen, 1976) para as rochas estudadas. Legendas: 1 a $5=$ trends evolutivos das séries granitoides (Lameyre \& Bowden, 1982; Bowden et al., 1984); BEpTrd = biotita-epidoto-trondhjemito; ABGrd = anfibólio-biotitagranodiorito; BGrd = biotita-granodiorito; LGrdG = leucogranodioritos-granitos.

apatita, opacos, epidoto e titanita como principais fases acessórias, e mica branca, clorita e epidoto (substituindo plagioclásio, biotita e hornblenda) como fases secundárias. Os LGrdG apresentam conteúdos de plagioclásio variando, respectivamente, de 40,8 a 55,8\% e 23,6 a $34,6 \%$, quartzo de 24 a $44 \%$ e 22,8 a $40,2 \%$ e álcali feldspato de 7 a 19,8\% e 29,8 a 44,3\%. A biotita é a principal fase máfica dessas rochas, com conteúdos modais de 1,8 a $7 \%$ nas rochas leucogranodioríticas e 1,9 a 4,5\% nas monzograníticas. Minerais opacos, apatita e titanita são as principais fases acessórias.

\section{ASPECTOS TEXTURAIS}

As rochas BEpTrd possuem textura original modificada em diferentes intensidades. Os cristais de quartzo são os mais afetados pela recristalização, seguidos dos cristais de plagioclásio. Micas primárias e secundárias mostram planos de clivagem dobrados, corroborando a existência de deformação. A saussuritização do plagioclásio é um processo intenso nessas rochas.
Os ABGrd destacam-se pela coloração cinza com tons esverdeados, em decorrência do intenso processo de saussuritização dos cristais de plagioclásio. Apresentam textura equigranular média a grossa dominante e enclaves máficos alongados de composição quartzo-diorítica. Microscopicamente, essa unidade tem seus cristais de plagioclásio moderada a intensamente saussuritizados, além de hornblenda, biotita e epidoto magmático como principais fases máficas. A assembleia de minerais acessórios inclui zircão, apatita, magnetita, titanita e allanita. Os cristais de hornblenda são subidiomórficos, bem preservados, com contatos retos com o epidoto magmático e alterados parcialmente nas bordas para biotita e, ao longo dos planos de clivagem, para titanita e epidoto. A biotita forma cristais subidiomórficos, com substituição por titanita ao longo de seus planos de clivagem; inclusões de zircão são comuns. Alguns cristais mostram planos de clivagem encurvados e seguem direção preferencial, definindo leves planos de foliação; tais orientações são mais comuns em torno dos cristais de plagioclásio.

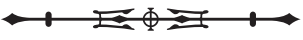


Os BGrd apresentam texturas definidas com base nos diferentes graus de deformação, que variam de discreto a intenso, gerando texturas protomiloníticas a miloníticas, com forte recristalização de quartzo apresentando junções tríplices. Subgrãos manteando cristais de plagioclásio e microclina (textura 'mortar') assumem a forma de porfiroclastos contornados por matriz fina recristalizada e lamelas de biotita, que definem leves planos de foliação. Mirmequita na forma de colônia é comum entre cristais de microclina e plagioclásio. A muscovita está presente em quantidade considerável nessas rochas (Tabela 2) como inclusões bem desenvolvidas nos cristais de plagioclásio ou, localmente, mostrando contato reto com este último, sugerindo origem magmática. Vernon (2004) sugere que o intercrescimento mirmequítico é típico de rochas granitoides deformadas (augen gnaisses e milonitos félsicos) que apresentam microclina com geminação oticamente visível, sugerindo que a formação de mirmequita está ligada à deformação no estado sólido. Simpson \& Wintsch (1989) sugerem que Ca e Na liberados do plagioclásio podem ser transferidos para a mirmequita, que substitui a microclina, a partir da qual o K pode ser transferido para a muscovita desenvolvida no plagioclásio. Desse modo, o teor e tamanho das muscovitas podem estar relacionados com a formação desse intercrescimento, que forneceria o K suficiente para o crescimento da mica.

Os LGrdG apresentam coloração esbranquiçada com tons rosados. Os pórfiros de plagioclásio e álcali feldspato rosado destacam-se em relação aos demais cristais, dando um aspecto distinto das outras unidades. Os cristais de plagioclásio ocorrem sob a forma de cristais subidiomórficos, variando de 0,5 a 3,4 mm. Seus contatos mútuos e com as lamelas de biotita são retos, porém passam a irregulares com o quartzo. Sofrem processo de saussuritização, sobretudo em seus núcleos, evidenciando a composição mais cálcica dessas porções. Os cristais de quartzo ocorrem em quatro tipos distintos: Qz1 - cristais xenomórficos a subidiomórficos (1,0 a 3,8 mm), com forte extinção ondulante e contatos irregulares principalmente com plagioclásio e microclina; Qz2 - agregados policristalinos exibindo textura em mosaicos, com formas poligonais e contatos retos em junção tríplice; Qz3 - quartzo vermicular ou goticular na forma de intercrescimento granofírico; Qz4 - inclusões em pórfiros de microclina. A microclina é subidiomórfica $(0,4$ a $3 \mathrm{~mm})$, com contatos retos entre si e irregulares com os outros minerais. As pertitas são do tipo string (Smith, 1974). Quartzo granular e cristais prismáticos de plagioclásio desenvolvem feições poiquilíticas. A biotita forma cristais subidiomórficos $(\sim 0,5 \mathrm{~mm})$, mostra contatos retos com os cristais de plagioclásio e álcali feldspato, porém, em alguns casos, com terminações serrilhadas. Encontra-se fortemente alterada para clorita, titanita e muscovita.

\section{GEOQUÍMICA}

\section{PROCEDIMENTOS ANALÍTICOS}

As análises químicas (Tabela 3) foram realizadas no Analytical Laboratories LTD. (ACME) e envolveram a determinação de elementos maiores e menores $\left(\mathrm{SiO}_{2}\right.$, $\mathrm{TiO}_{2}, \mathrm{Al}_{2} \mathrm{O}_{3}, \mathrm{Fe}_{2} \mathrm{O}_{3}, \mathrm{FeO}, \mathrm{MgO}, \mathrm{CaO}, \mathrm{MnO}, \mathrm{Na}_{2} \mathrm{O}, \mathrm{K}_{2} \mathrm{O}$, $\mathrm{P}_{2} \mathrm{O}_{5}$ ), analisados por Inductively Coupled Plasma-Emission Spectrometry (ICP-ES), e de elementos-traço (Rb, Sr, Ba, $\mathrm{Ga}, \mathrm{Y}, \mathrm{Zr}, \mathrm{Nb}, \mathrm{U}, \mathrm{Th}, \mathrm{Cr}, \mathrm{Ni}, \mathrm{V}$ ), incluindo os terras raras (La, Ce, Nd, Sm, Eu, Gd, Dy, Er, Yb e Lu), analisados por Inductively Coupled Plasma-Mass Spectrometry (ICP-MS).

\section{ASSOCIAÇÃO GRANODIORÍTICA}

\section{Elementos maiores e menores}

Variação dos elementos maiores e menores da associação granodiorítica estudada, além dos campos de ocorrência dos sanukitoides Rio Maria (M. A. Oliveira et al., 2009) e leucogranodioritos-granitos da Suíte Guarantã (Almeida et al., 2010) são apresentados na Figura 6. 


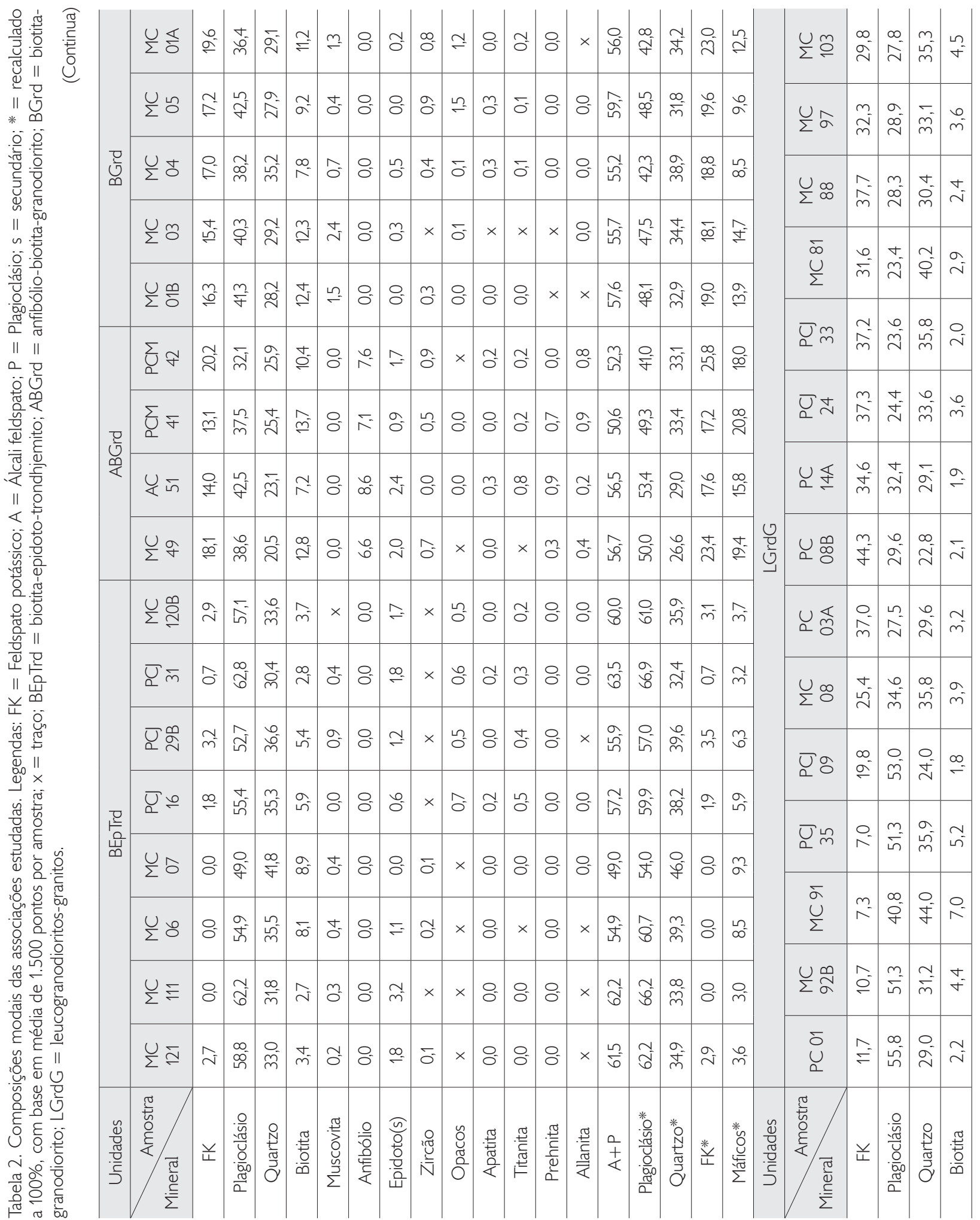




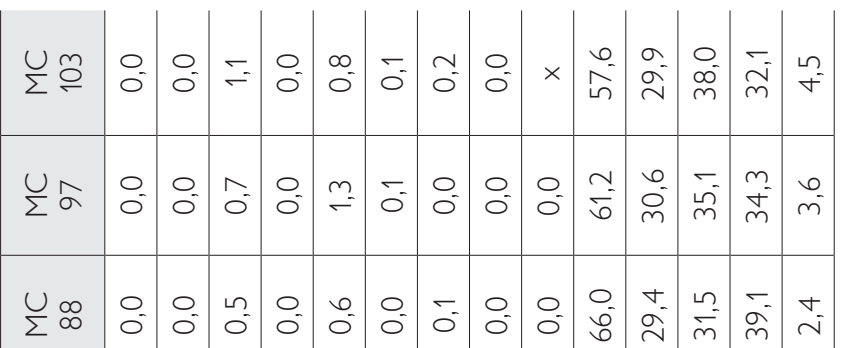

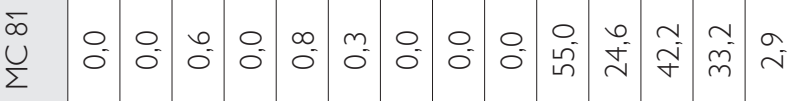

অ̄m

Ū

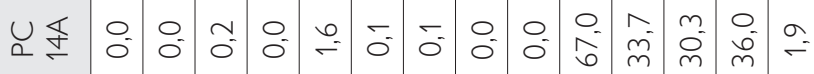

J

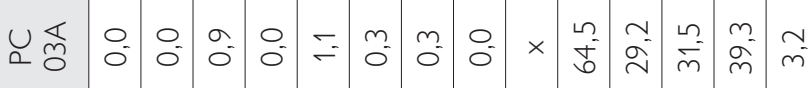

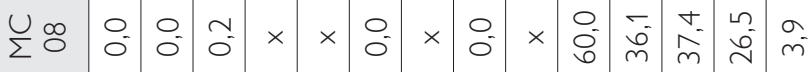

ত্রু

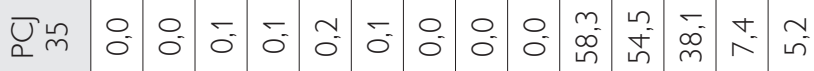

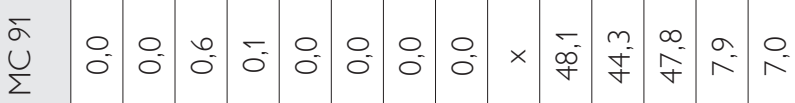

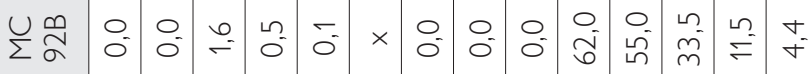

joj. 
Os ABGrd mostram os menores conteúdos de $\mathrm{SiO}_{2}(65,46$ a 66,20\%), enquanto BGrd e LGrdG possuem teores de $\mathrm{SiO}_{2}$ mais elevados, variando de 69,36 a 71,89\% e 70,85 a $71,54 \%$, respectivamente. $\mathrm{MgO}, \mathrm{TiO}_{2}, \mathrm{CaO}, \mathrm{P}_{2} \mathrm{O}_{5}, \mathrm{Al}_{2} \mathrm{O}_{3}$ e $\mathrm{FeO}_{t}$ decrescem (Figuras 6A-6F), enquanto $\mathrm{Na}_{2} \mathrm{O}$ e $\mathrm{K}_{2} \mathrm{O}$ tendem a aumentar paralelamente ao crescimento de $\mathrm{SiO}_{2}$ (Figuras 6G-6H). $\mathrm{O} \mathrm{Al}_{2} \mathrm{O}_{3}$ é semelhante ao das séries cálcioalcalinas (Irvine \& Baragar, 1971; Peccerillo \& Taylor, 1976); varia de 14,75 a $15,71 \%$ nos $A B G r d ; 14,56$ a $16,11 \%$ nos BGrd; e 15,81 a 16,40\% nos LGrdG (Tabela 3).

\section{Elementos-traço}

Em séries magmáticas, a variação de elementos-traço reflete a diferenciação e pode subsidiar a interpretação dos processos responsáveis pela sua evolução, uma vez que a distribuição desses elementos é controlada pelas fases minerais fracionadas durante a cristalização do magma (Wedepohl, 1970; Hanson, 1978). O comportamento dos principais elementos-traço pode ser visualizado nos diagramas de Harker (Figura 7), onde as rochas estudadas podem ser claramente individualizadas. Os ABGrd mostram trends levemente negativos para $\mathrm{Ba}, \mathrm{Rb}$ e Sr (Figuras 7A-7C). São mais enriquecidos em Ni (44,361,9 ppm; Figura 7H) e Cr (151-171 ppm; Tabela 3) do que os BGrd (4,1-7,0 ppm e < 14 ppm, respectivamente) e LGrdG (2,8-5,2 ppm e < 14 ppm, respectivamente). Os valores de \#Mg variam de 0,50 a 0,57 nos ABGrd, 0,27 a 0,36 nos BGrd e de 0,39 a 0,49 nos LGrdG (Tabela 3).

Os LGrdG apresentam enriquecimento em Ba (410 a 1.522 ppm) e Sr (596 a 668 ppm) e uma leve correlação positiva em relação à sílica (Figuras 7A, 7C). Por outro lado, mostram baixos conteúdos de Rb (30 a 45 ppm), Y (1,3 a 31 ppm), Zr (60 a 77 ppm), La (19 a 48 ppm, com uma amostra com 315 ppm) e Ce (13 a 51 ppm), quando comparados aos ABGrd e BGrd (Figuras 7B, 7D-7G).

Os BGrd são pobres em Ba (319a 905 ppm)e Sr (248 a 370 ppm), em relação aos ABGrd e LGrdG (Figuras 7A, 7C), embora o Ba mostre leve correlação positiva com a sílica. Rb, Zr, La e Ce mostram correlação positiva com a sílica e são, de modo geral, coincidentes a superiores em relação aos valores encontrados nos ABGrd e LGrdG (Figuras 7B, 7E7G). Os teores de Ni são baixos e similares aos das rochas LGdrG e agrupam-se no diagrama $\mathrm{Ni} \times \mathrm{SiO}_{2}$ (Figura $\left.7 \mathrm{H}\right)$. As razões $\mathrm{Rb} / \mathrm{Sr}$ e $\mathrm{Sr} / \mathrm{Ba}$ permitem uma boa distinção entre os três litotipos. No diagrama Rb/Sr versus $\mathrm{SiO}_{2}$ (Figura 8A), os LGrdG mostram as menores razões $(0,05-0,07)$, contrariamente aos BGrd, que possuem razões mais elevadas e variáveis $(0,20-0,49)$, enquanto os ABGrd assumem valores intermediários (0,21 a 0,32). No diagrama Sr/Ba versus $\mathrm{SiO}_{2}$ (Figura 8B), BGrd e LGrdG mostram razões próximas a coincidentes $(0,31$ a 0,56 e 0,40 a 0,63 , respectivamente), com exceção de duas amostras que apresentam valores mais elevados (0,87 e 1,5, respectivamente). Os ABGrd, embora apresentem razões $\mathrm{Sr} / \mathrm{Ba}$ similares às dos $\mathrm{LGrdG}(0,43$ a 0,63$)$, são mais pobres em silica, permitindo sua separação dos outros dois conjuntos de rochas. Nos diagramas envolvendo \#Mgversus $\mathrm{SiO}_{2}$ (Figura 8C) e Ni versus \#Mg (Figura 8D), a distinção entre os três grupos de rochas é nítida, com os ABGrd mostrando os maiores valores para \#Mg e teores de $\mathrm{Ni}$, similarmente ao observado nos sanukitoides Rio Maria, seguidos dos LGrdG e BGrd.

Os elementos terras raras (ETR) foram normalizados em relação aos condritos (Nakamura, 1974). ABGrd e BGrd mostram padrões de fracionamento contínuos e levemente similares (Figura 9A), com enriquecimento acentuado de elementos terras raras leves (ETRL) em relação aos elementos terras pesados (ETRP). As razões $\mathrm{La} / \mathrm{Yb}_{\mathrm{N}}$ do BGrd variam de 42,67 a 97,30, indicando que essas rochas são mais fracionadas do que os $A B G r d$, com razões $\mathrm{La} / \mathrm{Yb}_{\mathrm{N}}$ entre 22,53 e 46,31 (Tabela 3). As anomalias negativas de Eu são, de um modo geral, inexpressivas no ABGrd (Eu/ $\left.\mathrm{Eu}^{*}=0,76-0,87\right)$ e comparativamente mais acentuadas no BGrd (Eu/Eu* $=0,33-1,04)$.

Os LGrdG apresentam conteúdos de ETRL e ETRP inferiores ao das rochas da Suíte Guarantã, com exceção da amostra PC-03A, que se sobressai às demais (Figura 9B). Entretanto, o padrão tende a ser similar, com forte fracionamento dos ETRL em relação aos ETRP 
$\left(\mathrm{La} / \mathrm{Yb}_{\mathrm{N}}=24,31\right.$ a 46,65; Tabela 3). As anomalias de Eu dos LGrdG são muito discretas, podendo ser levemente positivas ou levemente negativas (Eu/Eu* $=0,59-1,46)$.

\section{Séries magmáticas}

Tendo a hornblenda como principal fase máfica, os ABGrd plotam no campo das rochas metaluminosas, implicando excesso de $\mathrm{CaO}+\mathrm{Na}_{2} \mathrm{O}+\mathrm{K}_{2} \mathrm{O}$ mol em relação ao $\mathrm{Al}_{2} \mathrm{O}_{3}$ mol. Os BGrd e LGrdG, por outro lado, plotam no campo das rochas fracamente peraluminosas (Figura 10A). No diagrama normativo An-Ab-Or (Figura 10B), os ABGrd caem no campo das rochas granodioríticas, enquanto os BGrd plotam no campo das rochas tonalíticas e graníticas, porém próximo ao campo granodiorítico. Os LGrdG são mais enriquecidos em albita normativa e incidem no campo das rochas trondhjemíticas. No diagrama AFM (Figura 10C), todas as amostras plotam no campo das rochas cálcio-alcalinas e mostram comportamento similar, com decréscimo nos conteúdos de $\mathrm{MgO}$ e $\mathrm{FeO}_{\mathrm{t}}$ e aumento nos de álcalis. A assinatura cálcio-alcalina dessas rochas é ressaltada também no diagrama $\mathrm{K}_{2}$ O versus $\mathrm{SiO}_{2}$ (Figura 10D), no qual os $\mathrm{ABGrd}$ e BGrd são dominantes no campo das rochas cálcio-alcalinas de alto potássio, com duas amostras de BGrd ocupando o campo de médio potássio. Os LGrdG plotam no das rochas cálcio-alcalinas de médio potássio, com uma amostra incidindo no campo da série toleítica ou de baixo potássio.

\section{ASSOCIAÇÃO TRONDHJEMÍTICA}

\section{Elementos maiores}

As amostras do BEpTrd apresentam conteúdos de sílica variando de 68,05 a 70,43\%. $\mathrm{Al}_{2} \mathrm{O}_{3}$ é elevado e situa-se entre 15,39 e 16,87. $\mathrm{Fe}_{2} \mathrm{O}_{3}, \mathrm{CaO}$ e $\mathrm{MgO}$ variam de 2,69 a 3,30\%, 3,07 a 3,58\% e 0,81 a 0,95\%, respectivamente (Tabela 3). $\mathrm{Na}_{2} \mathrm{O}$ e $\mathrm{K}_{2} \mathrm{O}$ possuem teores entre 4,41 e $5,32 \%$ e 0,85 e 1,47\%, respectivamente. $\mathrm{Al}_{2} \mathrm{O}_{3}$ e $\mathrm{Na}_{2} \mathrm{O}$ apresentam correlação negativa com a sílica (Figuras 11B, 11D), enquanto $\mathrm{CaO}$ e $\mathrm{MgO}$ não definem trends claros (Figuras 11A, 11C).

\section{Elementos-traço}

O comportamento dos elementos-traço Rb, Ba e Zr é mostrado na Figura 11. Os teores de Rb (29,3 a 48,2 ppm) e $\operatorname{Zr}$ (51,7-113,4 ppm) são baixos, porém mostram uma leve correlação positiva com a sílica (Figuras 11E, 11G), enquanto os de $\mathrm{Ba}$ (333 a 618 ppm) e Sr (278,5-516,8 ppm) são moderados e apresentam correlação negativa com o aumento do teor de sílica, comportando-se como elementos compatíveis (Ba, Figura 11F; Sr, Tabela 3). Y (1,84,6 ppm) e Nb (0,7-4,8 ppm) não mostram correlação clara com a sílica (Tabela 3).

Os ETR (Tabela 3) foram normalizados pelos valores dos condritos de Nakamura (1974). Os BEpTrd mostram conteúdos de ETR variando de 203 a 432 ppm (Tabela 3) e enriquecimento em ETRL em relação aos ETRP, resultando em um padrão fortemente fracionado $\left(\mathrm{La} / \mathrm{Yb}_{\mathrm{N}}\right.$ $=90,54-32,74)$ e anomalias de Eu inexpressivas (Eu/Eu* = 0,80-1,1), com exceção da amostra MC-07, que apresenta anomalia positiva ( $\mathrm{Eu} / \mathrm{E} \mathrm{u}^{*}=1,85$; Figura 12F). $\mathrm{O}$ padrão de fracionamento dos ETR dos BEpTrd foi comparado com aqueles do Tonalito Arco Verde, Trondhjemito Água Fria, Tonalito Mariazinha, Trondhjemito Mogno e Complexo Tonalítico Caracol (Figuras 12A-12E), mostrando maior semelhança com os do Trondhjemito Mogno e Trondhjemito Água Fria (Figura 12G).

Almeida et al. (2011), com base em razões La/ $\mathrm{Yb}, \mathrm{Sr} / \mathrm{Y}$ e Nb/Ta, distinguem três principais grupos de granitoides arqueanos do TGGRM. O grupo 1 é formado por granitoides onde essas três razões são elevadas, sendo representado principalmente pelo Trondhjemito Mogno e Tonalito Mariazinha. O grupo 2 constitui-se de rochas com razões La/Yb, Sr/Y e Nb/Ta intermediárias e tem como representantes o Complexo Tonalítico Caracol e o Trondhjemito Água Fria, enquanto o grupo 3 possui rochas com baixas razões La/Yb, Sr/Y e Nb/Ta, sendo dominado pelo Tonalito Arco Verde. Os BEpTrd deste estudo mostram similaridades com as rochas granitoides do grupo 1, que apresentam altas razões $\mathrm{La} / \mathrm{Yb}, \mathrm{Sr} / \mathrm{Y}$ e Nb/Ta (Figura 13).

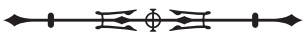




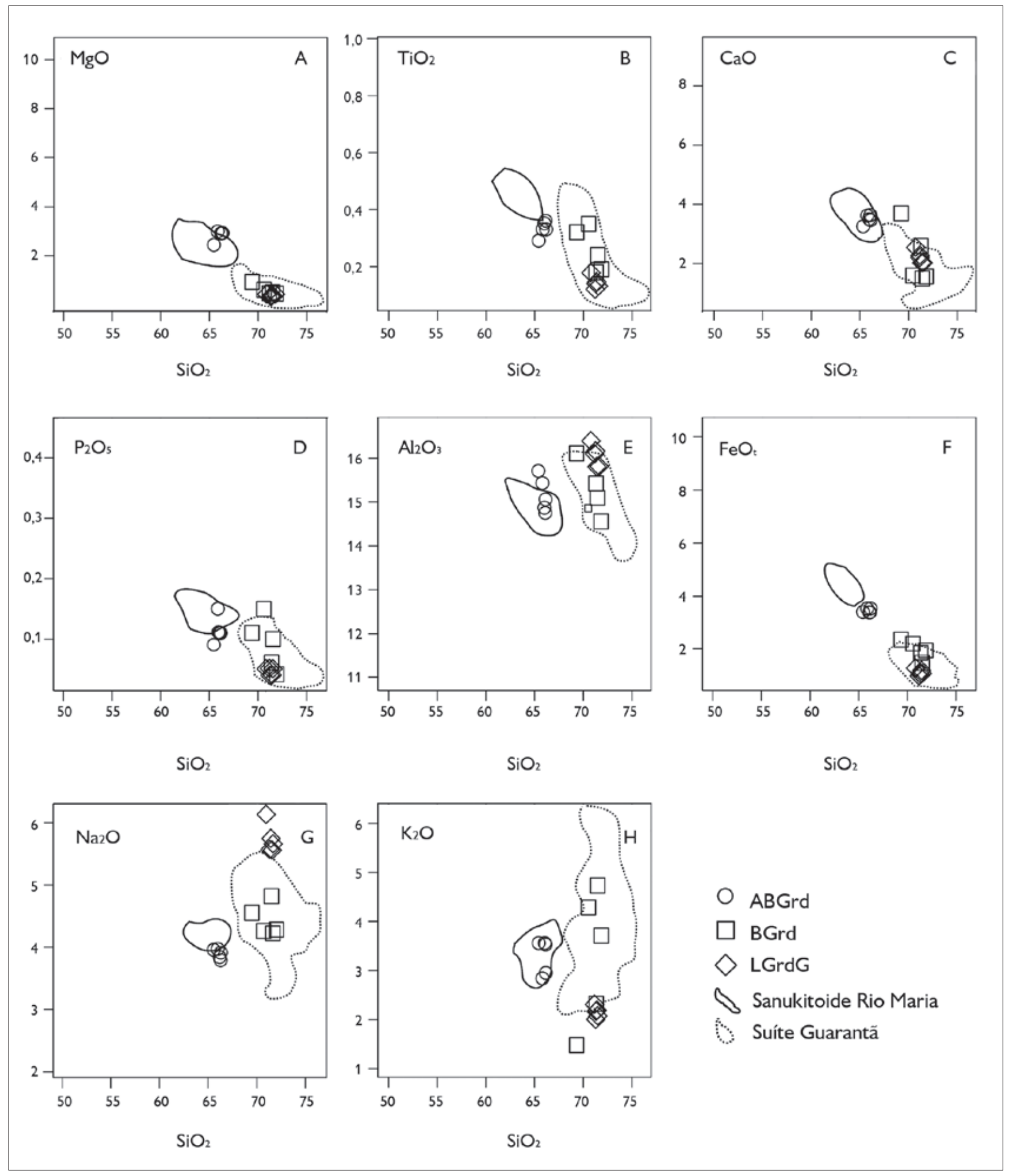

Figura 6. Diagramas de Harker para elementos maiores e menores da associação granodiorítica estudada. Suíte Sanukitoide Rio Maria (M. A. Oliveira et al., 2009) e leucogranodioritos-granitos da Suíte Guarantã (Almeida et al., 2010) são colocados para comparação. A) MgO; B) $\mathrm{TiO}_{2}$; C) $\mathrm{CaO}$; D) $\mathrm{P}_{2} \mathrm{O}_{5}$; E) $\mathrm{Al}_{2} \mathrm{O}_{3}$; F) $\mathrm{FeO}_{\mathrm{t}}$; G) $\mathrm{Na}_{2} \mathrm{O}$; H) $\mathrm{K}_{2} \mathrm{O}$. 


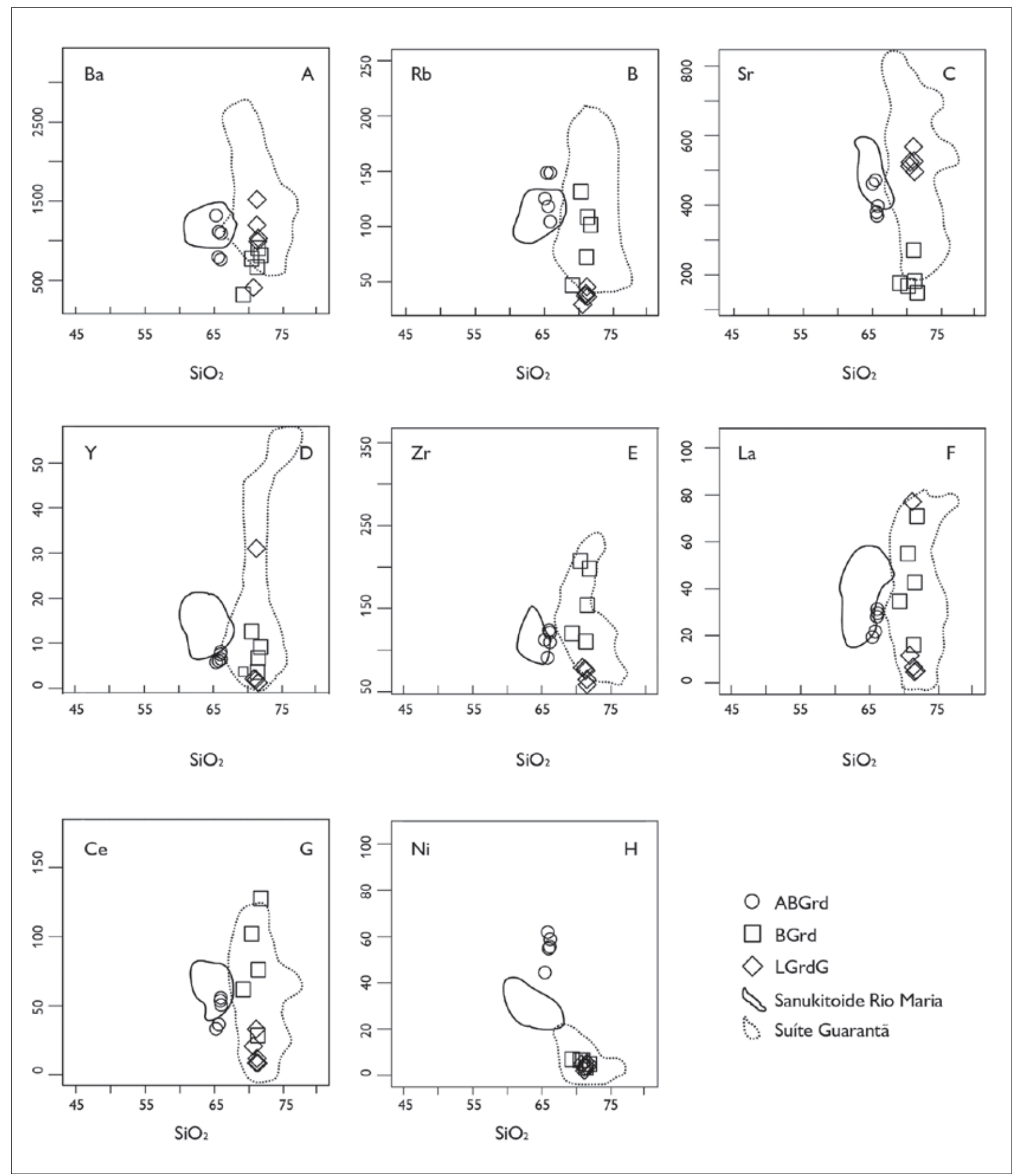

Figura 7. Diagramas de Harker para elementos-traço das amostras da associação granodiorítica estudada. Campos das rochas da Suíte Sanukitoide Rio Maria (M. A. Oliveira et al., 2009) e leucogranodioritos-granitos da Suíte Guarantã (Almeida et al., 2010) são mostrados para comparação. A) Ba; B) Rb; C) Sr; D) Y; E) Zr; F) La; G) Ce; H) Ni. 


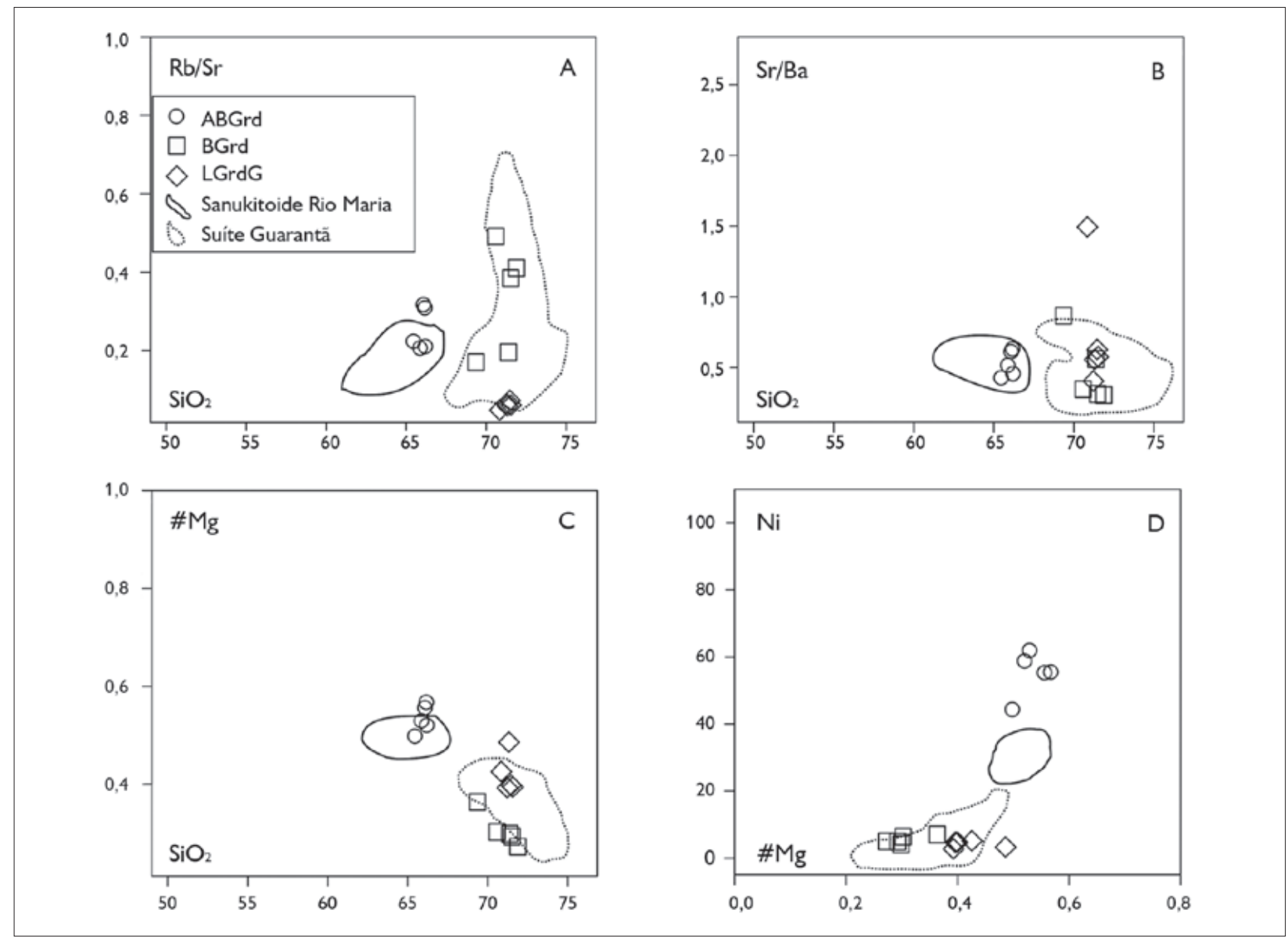

Figura 8. Diagramas de Harker para as razões Rb/Sr (A), Sr/Ba (B), \#Mg (C) e diagrama \#Mg versus Ni (D) para as rochas estudadas. Campos das rochas da Suíte Sanukitoide Rio Maria e da Suíte Guarantã são mostrados para comparação.

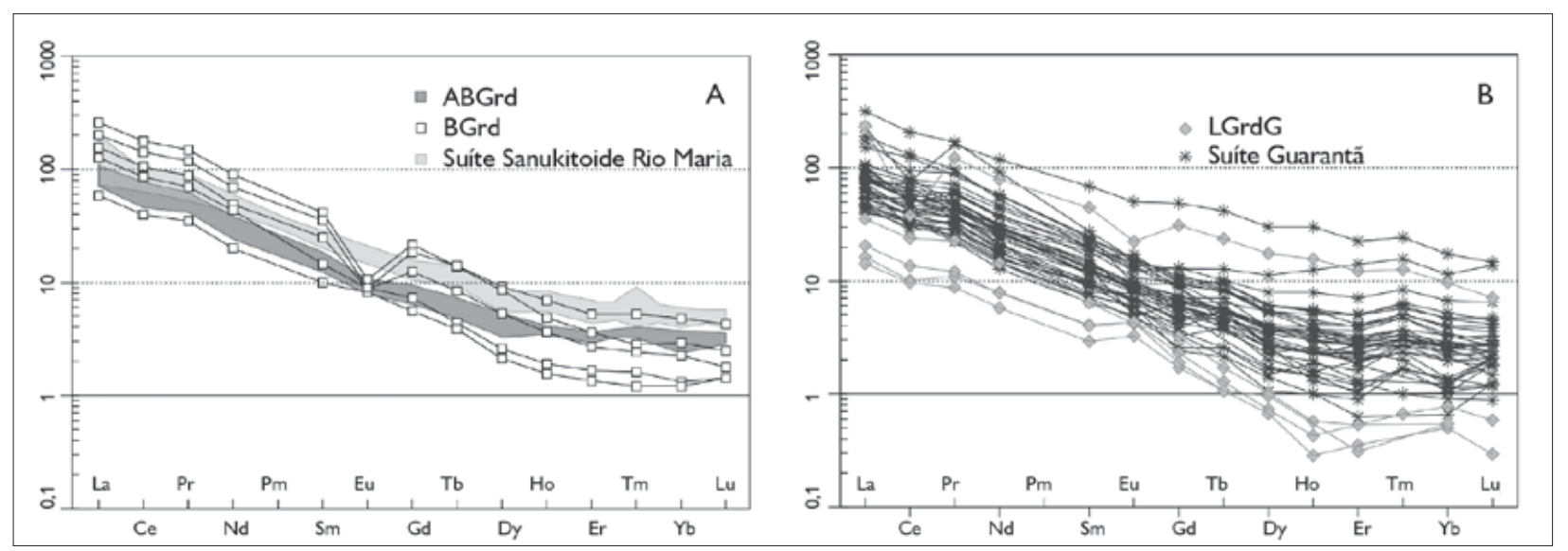

Figura 9. A) Padrões de elementos terras raras das rochas granodioríticas estudadas comparadas com as da Suíte Sanukitoide Rio Maria (M. A. Oliveira et al., 2009); B) padrões de elementos terras raras dos LGrdG deste estudo comparados com os das rochas da Suíte Guarantã (Almeida et al., 2010). Dados normalizados em relação ao condrito (Nakamura, 1974).

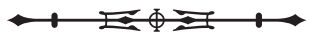




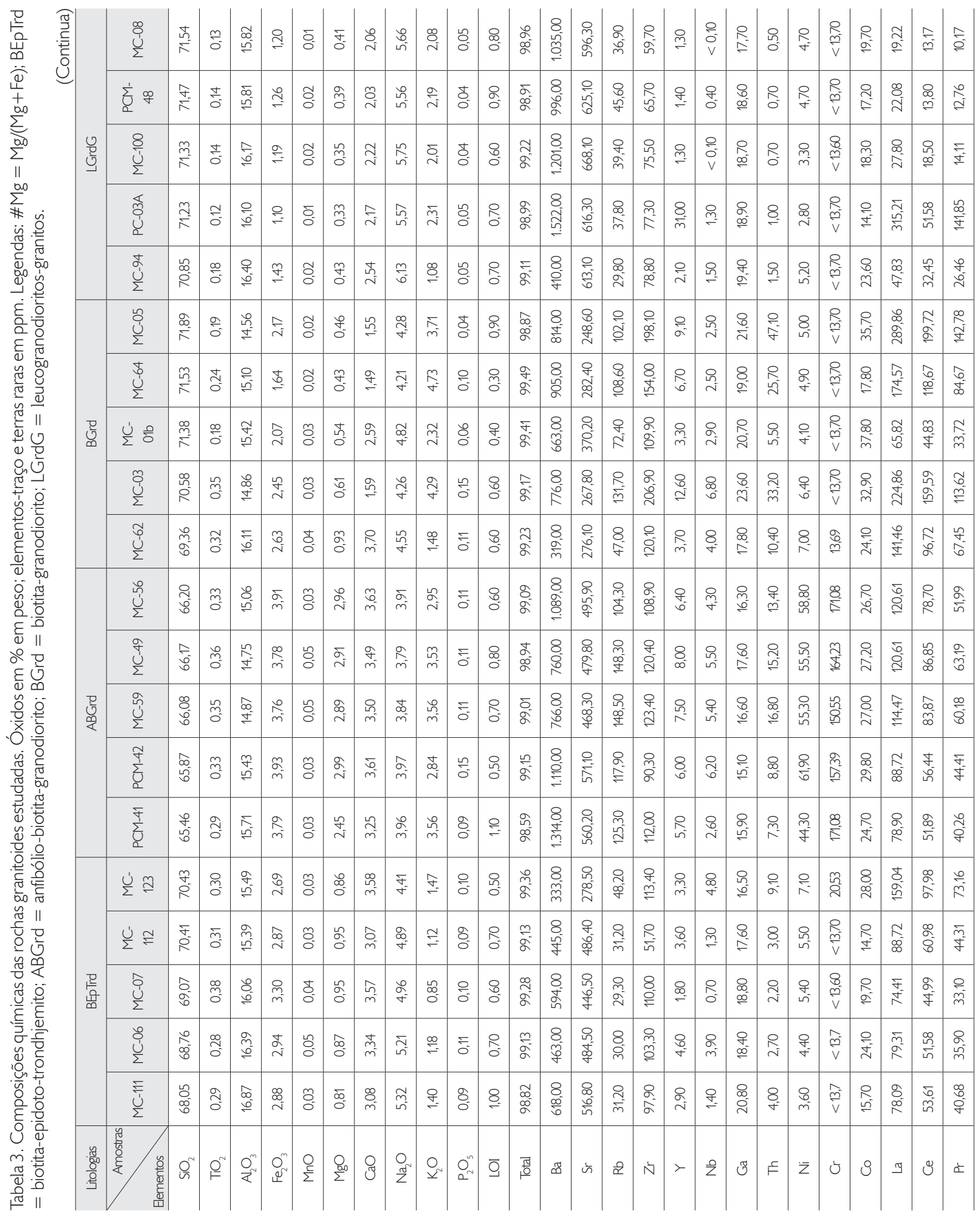




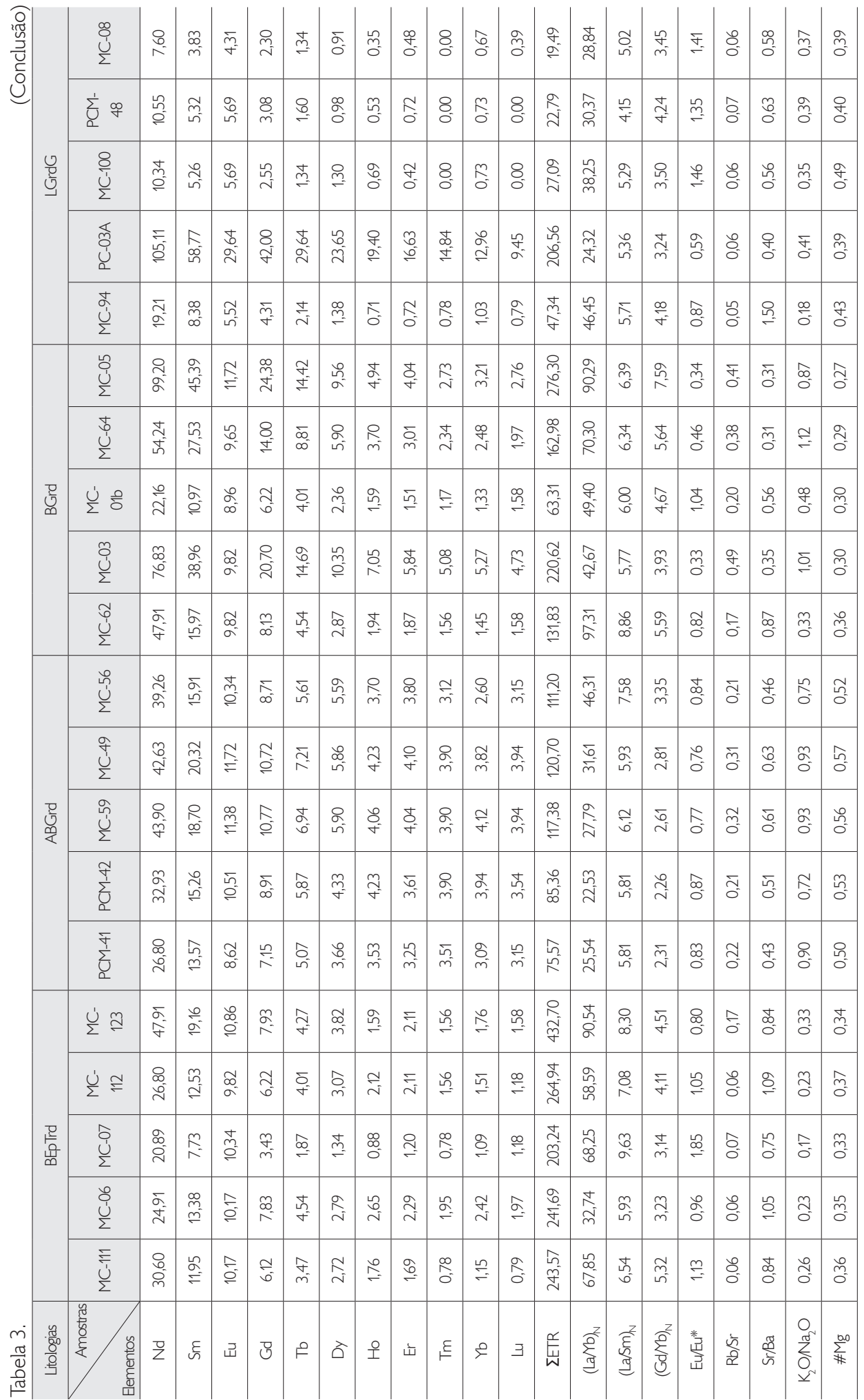



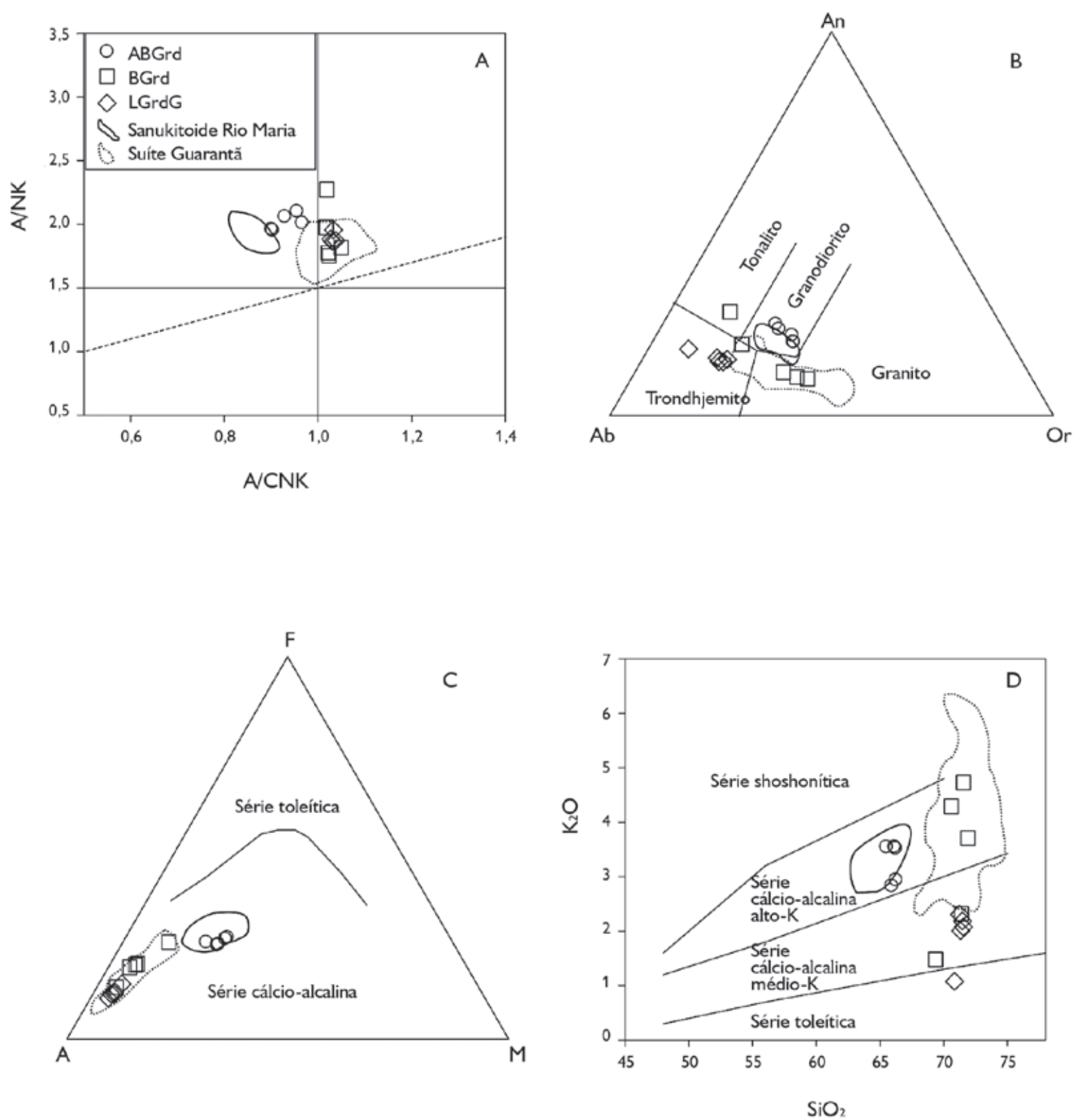

Figura 10. Diagramas geoquímicos mostrando a distribuição das amostras da associação granodiorítica deste estudo juntamente com os campos dos granodioritos das suítes sanukitoides Rio Maria e Guarantã. A) Diagrama ACNK versus ANK (Shand, 1950); B) diagrama AnAb-Or normativo (O'Connor, 1965, com campos de Barker, 1979); C) diagrama AFM (Irvine \& Baragar, 1971; $\mathrm{A}=\mathrm{Na} \mathrm{O}_{2} \mathrm{O}+\mathrm{K}_{2} \mathrm{O} ; \mathrm{F}=$ $\mathrm{FeO}+0,9 * \mathrm{Fe}_{2} \mathrm{O}_{3} ; \mathrm{M}=\mathrm{MgO}$ ); D) diagrama $\mathrm{K}_{2} \mathrm{O}$ versus $\mathrm{SiO}_{2}$, com campos de Peccerillo \& Taylor (1976).

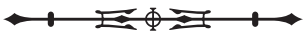



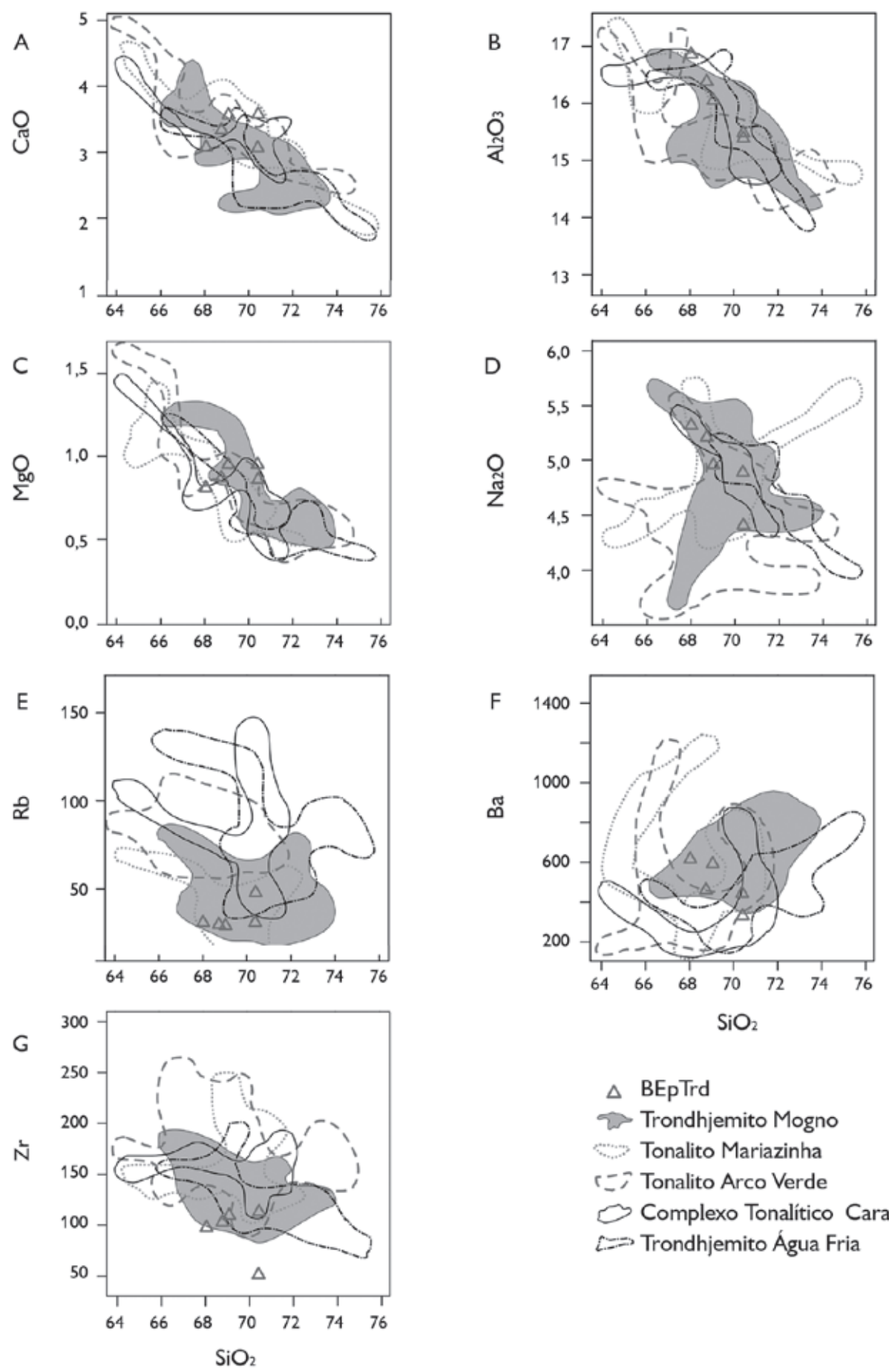

$\mathrm{SiO}_{2}$

$\triangle$ BEpTrd

w Trondhjemito Mogno

Tonalito Mariazinha

こニ- Tonalito Arco Verde

Complexo Tonalítico Caracol

$\Leftrightarrow$ Trondhjemito Água Fria

Figura 11. Diagramas de Harker para elementos maiores (A-D) e traço (E-G) das rochas trondhjemíticas deste estudo e de outras rochas TTG do TGGRM (campos baseados em Almeida et al., 2011). A) $\mathrm{CaO}$; B) $\mathrm{Al}_{2} \mathrm{O}_{3}$; C) MgO; D) $\mathrm{Na}_{2} \mathrm{O}$; E) Rb; F) Ba; G) Zr. 

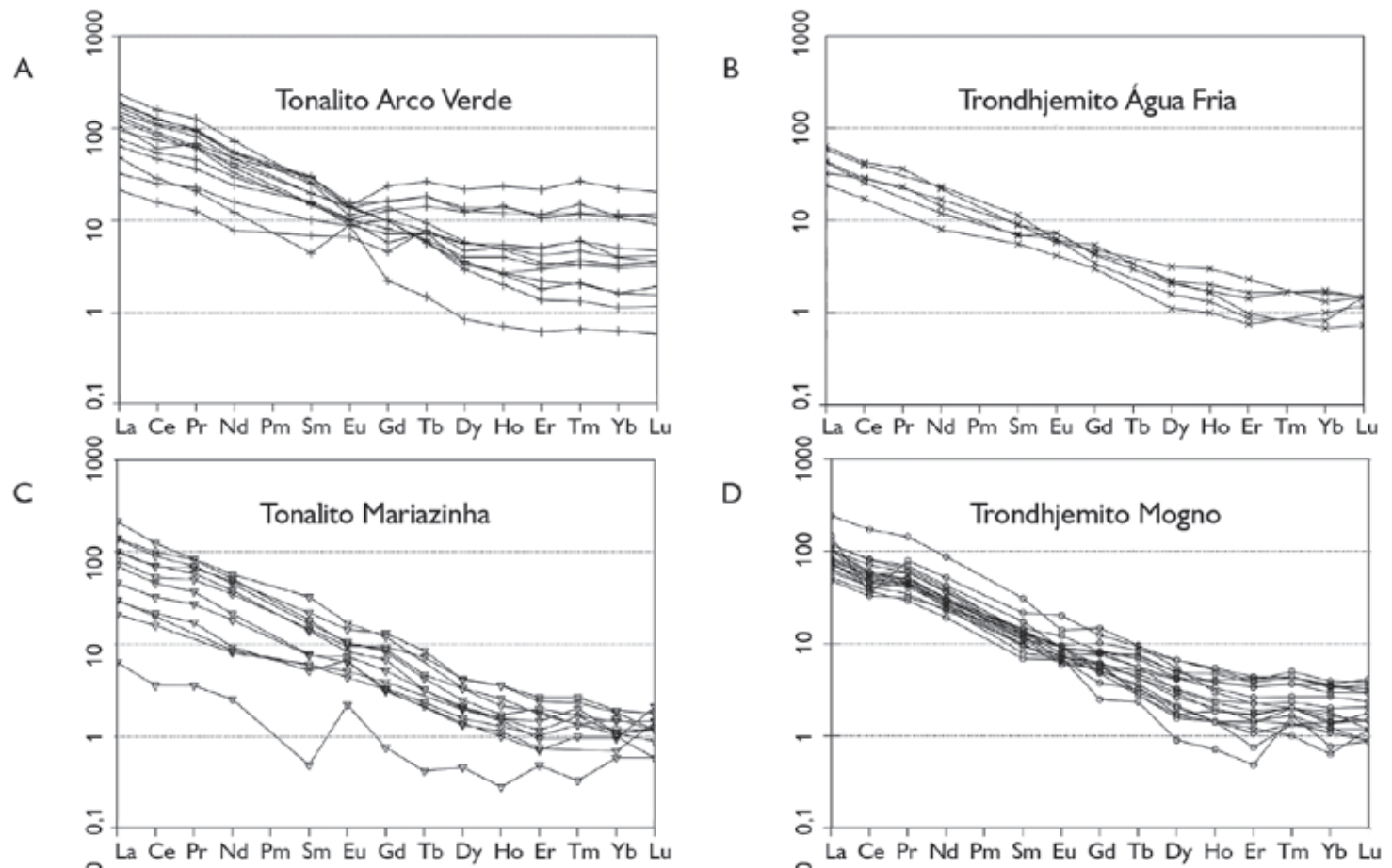

D

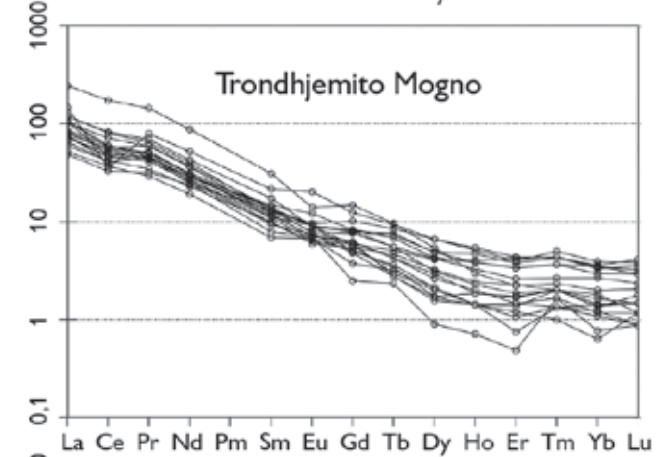

E
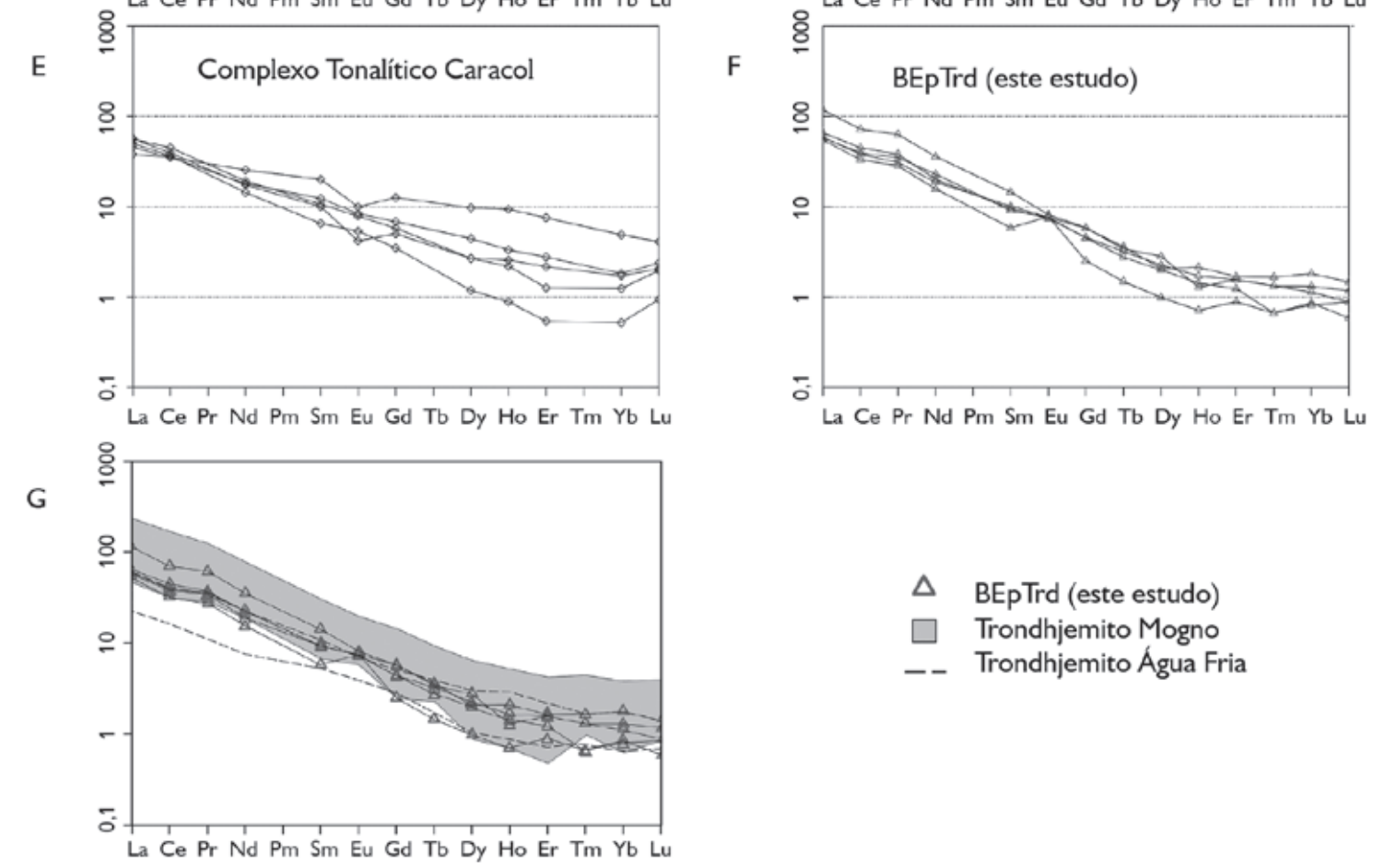

Figura 12. A-E) Padrões de ETR de rochas TTG estudadas por Almeida et al. (2011); F) padrões de ETR para as rochas da associação trondhjemítica deste estudo; G) comparação entre padrões de ETR. Dados normalizados em relação ao condrito (Nakamura, 1974).

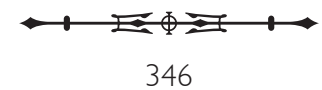




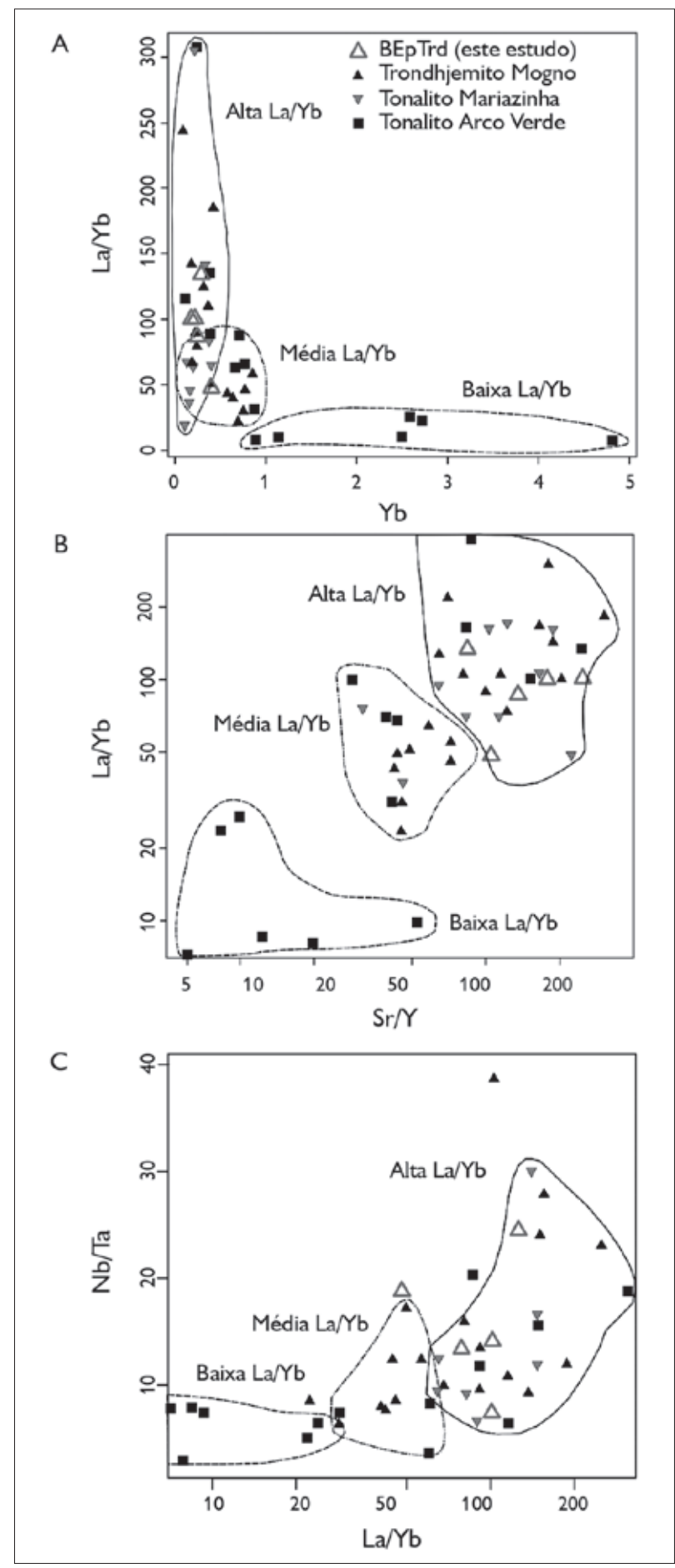

Figura 13. Diagramas La/Yb versus Yb (A), La/Yb versus Sr/Y (B) e Nb/ Ta versus La/Yb (C), utilizados para discriminar os diferentes grupos de granitoides TTG do Terreno Granito-Greenstone de Rio Maria, segundo Almeida et al. (2011).
Séries magmáticas

Os BEpTrd mostram assinatura leve a moderadamente peraluminosa no diagrama A/NK versus A/CNK (Shand, 1950), plotam na interface das rochas trondhjemíticas e tonalíticas no diagrama normativo An-Ab-Or (Figuras 14A-14B) e incidem no campo das rochas cálcio-alcalinas de baixo a médio-K (Figuras 14C-14D).

\section{GEOCRONOLOGIA}

\section{PROCEDIMENTOS ANALÍTICOS}

As análises isotópicas realizadas por meio do método de evaporação de Pb em monocristais de zircão foram efetuadas no Laboratório de Geologia Isotópica do Instituto de Geociências da Universidade Federal do Pará (IG-UFPA). A metodologia utilizada nas análises foi a desenvolvida por Kober (1986). As análises foram feitas em um espectrômetro de massa de ionização termal modelo FINNIGAN MAT 262. A separação cartográfica e petrográfica das unidades estudadas permitiu selecionar amostras representativas de duas delas, de modo a determinar suas idades de cristalização. Foram datadas as amostras MC-01Ae MC-49, representantes, respectivamente, dos BGrd aflorantes às proximidades da cidade de Água Azul do Norte e dos ABGrd da cidade de Ourilândia do Norte.

\section{RESULTADOS}

- BGrd: a amostra dessa unidade (MC-01A) é representativa do domínio nordeste da área de estudo. Foram selecionados 31 cristais translúcidos, marrons, bipiramidais, moderada a levemente fraturados e comumente zonados. Desses, 28 foram eliminados do cálculo da idade final, por apresentarem razões ${ }^{204} \mathrm{~Pb} /{ }^{206} \mathrm{~Pb}$ acima de 0,0004 ou conteúdos de $\mathrm{Pb}$ insuficientes para a datação. Os três cristais restantes forneceram uma idade média de 2884 $\pm 3 \mathrm{Ma}$, considerada, preliminarmente, idade de cristalização. A Tabela 4 mostra as idades obtidas para os três cristais de zircão, e a Figura 15, o diagrama com a idade média dos mesmos. 
- $\quad$ ABGrd: a amostra selecionada para datação geocronológica (MC-49) é representativa do domínio noroeste da área de estudo; possui aspecto textural primário preservado, padrões estruturais e petrográficos distintos das rochas granodioríticas da porção nordeste. Foram selecionados 54 cristais de coloração castanhoclara dominante, translúcidos, com certo brilho adamantino, de hábito prismático bipiramidal, moderada a levemente fraturados, comumente zonados e isentos de inclusões. Desses, 16 cristais foram analisados, sendo onze deles eliminados do cálculo da idade final por apresentarem razões ${ }^{204} \mathrm{~Pb} /{ }^{206} \mathrm{~Pb}$ acima de 0,0004 ou conteúdos de $\mathrm{Pb}$ insuficientes para datação. Cinco cristais apresentaram idade de $2875 \pm 2 \mathrm{Ma}$, interpretada como idade de cristalização da rocha (Tabela 5, Figura 15).
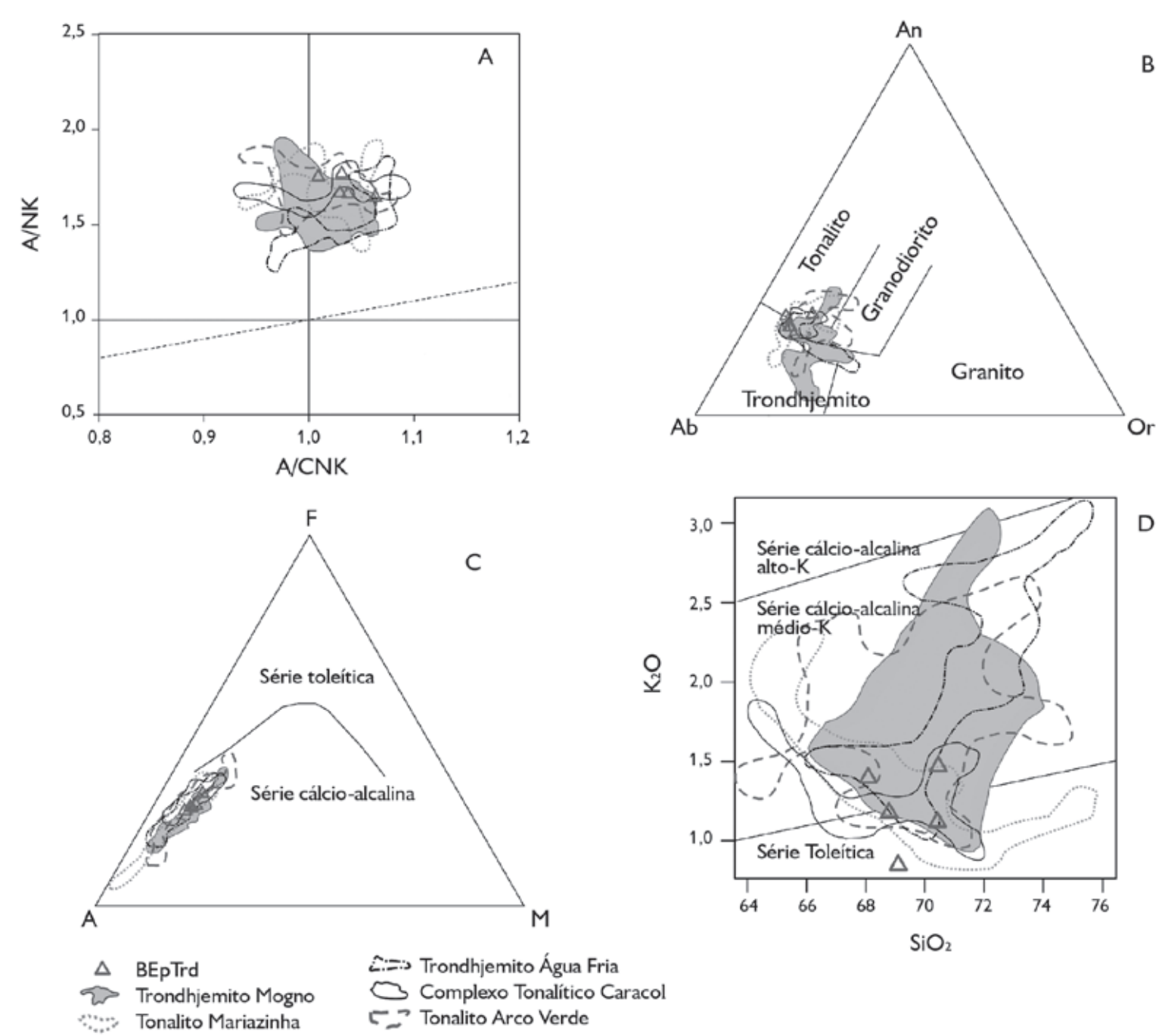

Figura 14. Diagramas mostrando a distribuição dos granitoides TTG da área de estudo comparados com aqueles estudados por Almeida et al., 2011. A) Diagrama ACNK versus ANK (Shand, 1950); B) diagrama An-Ab-Or normativo (O'Connor, 1965, com campos de Barker, 1979); C) diagrama AFM (Irvine \& Baragar, 1971; $\mathrm{A}=\mathrm{Na}_{2} \mathrm{O}+\mathrm{K}_{2} \mathrm{O} ; \mathrm{F}=\mathrm{FeO}+0,9 * \mathrm{Fe}_{2} \mathrm{O}_{3} ; \mathrm{M}=\mathrm{MgO}$ ); $\mathrm{D}$ ) diagrama $\mathrm{K}_{2} \mathrm{O}$ versus $\mathrm{SiO}_{2}$ (campos segundo Peccerillo \& Taylor, 1976).

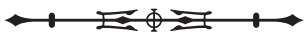




\section{DISCUSSÕES}

\section{COMPARAÇÕES COM OUTRAS UNIDADES DO TGGRM}

\section{ABGrd e BGrd versus Suíte Sanukitoide Rio Maria}

Os ABGrd e BGrd que ocorrem na porção NWN da área de estudo (Figura 4) são comparados às rochas granodioríticas da Suíte Sanukitoide Rio Maria (M. A. Oliveira et al., 2009). Os ABGrd apresentam composição mineralógica e modal similar à dos sanukitoides (Figura 5), possuem anfibólio e biotita como principais fases ferromagnesianas e epidoto magmático, mineral comumente presente nessas últimas. Mostram intensa saussuritização dos cristais de plagioclásio, que, juntamente com a presença de cristais de epidoto, proporcionam a coloração esverdeada característica das rochas sanukitoides Rio Maria. Por outro lado, os BGrd são texturalmente distintos, não possuem hornblenda, têm biotita como a única fase máfica, sendo o epidoto magmático uma fase ausente. Geoquimicamente, as amostras do ABGrd são coincidentes ou aproximam-se do campo de ocorrência dos sanukitoides Rio Maria nos diagramas envolvendo elementos maiores (Figura 6),

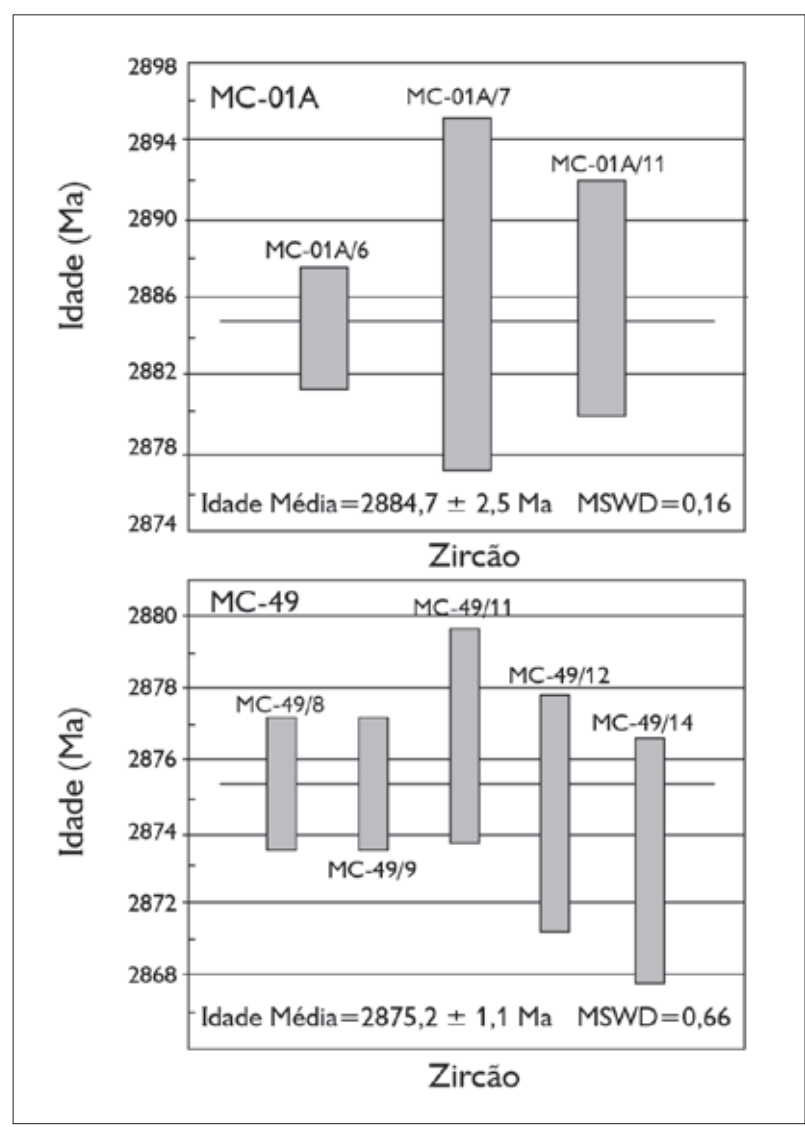

Figura 15. Diagramas mostrando as idades de cada cristal utilizado no cálculo da idade média das amostras MC-01A e MC-49.

Tabela 4. Resultado da datação por evaporação de Pb em zircão da amostra MC-01A

\begin{tabular}{c|c|c|c|c|c|c|c|c|c}
\hline Zircão & Razões & ${ }^{204} \mathrm{~Pb} /{ }^{206} \mathrm{~Pb}$ & $2 \mathrm{~s}$ & ${ }^{208} \mathrm{~Pb} /{ }^{206} \mathrm{~Pb}$ & $2 \mathrm{~s}$ & $\left({ }^{207} \mathrm{~Pb} /{ }^{006} \mathrm{~Pb}\right) \mathrm{c}$ & $2 \mathrm{~s}$ & Idade & $2 \mathrm{~s}$ \\
\hline MC01A/6 & $32 / 80$ & 0,000184 & 0,000028 & 0,04948 & 0,0007 & 0,20721 & 0,00039 & 2884,3 & 3,0 \\
\hline MC01A/7 & $24 / 46$ & 0,000748 & 0,000047 & 0,05842 & 0,0014 & 0,20746 & 0,00116 & 2886,2 & 9,0 \\
\hline MC01A/11 & $22 / 30$ & 0,000084 & 0,000009 & 0,04856 & 0,0006 & 0,20741 & 0,00078 & 2885,8 & 6,1 \\
\hline & $78 / 594$ & \multicolumn{1}{|c}{ Idade $=$} & 2884,7 & 2,6 \\
\hline
\end{tabular}

Tabela 5. Resultado da datação por evaporação de Pb em zircão da amostra MC-49.

\begin{tabular}{|c|c|c|c|c|c|c|c|c|c|}
\hline Zircão & Razões & ${ }^{204} \mathrm{~Pb} /{ }^{06} \mathrm{~Pb}$ & $2 s$ & $\left({ }^{208} \mathrm{~Pb} /{ }^{206} \mathrm{~Pb}\right) \mathrm{c}$ & $2 s$ & $\left({ }^{207} \mathrm{~Pb} /{ }^{206} \mathrm{~Pb}\right) \mathrm{c}$ & $2 s$ & Idade & $2 s$ \\
\hline MC49/8 & $30 / 90$ & 0,000066 & 0,000008 & 0,15703 & 0,00302 & 0,20610 & 0,00024 & 2875,4 & 1,9 \\
\hline MC49/9 & $28 / 28$ & 0,000006 & 0,000029 & 0,17507 & 0,00433 & 0,20613 & 0,00023 & 2876,2 & 3,1 \\
\hline MC49/11 & $38 / 42$ & 0,000019 & 0,000004 & 0,20493 & 0,00073 & 0,20627 & 0,00039 & 2876,7 & 3,0 \\
\hline MC49/12 & $36 / 42$ & 0,000057 & 0,000013 & 0,16240 & 0,06301 & 0,20598 & 0,00042 & 2874,5 & 3,3 \\
\hline \multirow[t]{2}{*}{ MC49/14 } & $40 / 70$ & 0,000034 & 0,000007 & 0,11150 & 0,00065 & 0,20581 & 0,00043 & 2873,2 & 3,4 \\
\hline & $172 / 466$ & & & & & & Idade $=$ & 2875,2 & 1,1 \\
\hline
\end{tabular}

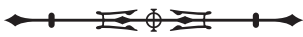


os elementos-traço Ba, Rb, Sr, Y, Zr, La e Ce (Figura 7) e as razões $\mathrm{Rb} / \mathrm{Sr}$ e $\mathrm{Sr} / \mathrm{Ba}$ (Figura 8). São também mais enriquecidas em $\mathrm{Ni}$ (44-62 ppm), $\mathrm{Cr}$ (150-171 ppm) e \#Mg $(0,50-0,57)$ em comparação com os sanukitoides Rio Maria ( $\mathrm{Ni}=25-31, \mathrm{Cr}=41-96, \# \mathrm{Mg}=0,48-0,50$; M. A. Oliveira et al., 2009).

Os BGrd, por outro lado, mostram comportamento distinto nesses elementos e razões. Em termos de elementos terras raras (Figura 9), os ABGrd são mais empobrecidos neles ( $\Sigma \mathrm{ETR}=75,6-120,7$ contra 104,5-253,8 dos sanukitoides), mostram ETRP um pouco mais fracionados $\left(\mathrm{Gd} / \mathrm{Yb}_{\mathrm{N}}=\right.$ 2,3-3,4 contra 1,3-1,6 dos sanukitoides), porém possuem padrão de fracionamento similar $\left(\mathrm{La} / \mathrm{Yb}_{\mathrm{N}}=22,5-46,3\right.$ contra 15,5-44,4 dos sanukitoides). Comparativamente, os BGrd são mais enriquecidos em ETR ( $\Sigma$ ETR entre 132-276 ppm, com apenas uma amostra com 63 ppm), evidenciando padrão mais fracionado para os ETR $\left(\mathrm{La}_{\mathrm{M}} \mathrm{Yb}_{\mathrm{N}}=42,7-97,3\right)$ e ETRP $\left(\mathrm{Gd} / \mathrm{Yb}_{\mathrm{N}}=3,9-7,6\right)$ e uma pronunciada anomalia negativa de Eu em relação à das rochas $A B G r d$ e sanukitoides (Figura 9). Tais características afastam a possibilidade de os BGrd serem uma fácies mais evoluída dos ABGrd. Quanto às séries magmáticas, os $A B G r d$ incidem, à semelhança dos sanukitoides Rio Maria, no campo granodiorítico no diagrama normativo An-Ab-Or, mostrando caráter metaluminoso e assinatura cálcio-alcalina de alto-K (Figura 10). Por outo lado, as rochas BGrd mostram comportamento diferente nesses diagramas e tendem a se afastar dos ABGrd e do campo dos sanukitoides, sugerindo tratar-se de outra unidade.

Os dados geocronológicos obtidos (Tabelas 4 e 5; Figura 15) indicaram idade de cristalização de $2875 \pm 2 \mathrm{Ma}$ para o ABGrd, similar às idades dos sanukitoides Rio Maria (dominantemente 2,87 Ga; Tabela 1). O BGrd forneceu idade de cristalização um pouco mais antiga (2884 \pm 3 $\mathrm{Ma}$ ), embora com apenas três cristais datados. Os dados petrográficos e geoquímicos deste trabalho, somados à idade de cristalização $\mathrm{Pb}-\mathrm{Pb}$ em zircão, indicam que o ABGrd que ocorre na região de Ourilândia do Norte é, em termos gerais, correlacionável aos granodioritos da Suíte Sanukitoide Rio Maria. Por outro lado, os BGrd que ocorrem imediatamente a leste dos ABGrd (Figura 4) apresentaram características petrográficas, geoquímicas e idade de cristalização diferentes, sugerindo tratar-se de outra unidade.

\section{LGrdG versus Suíte Guarantã}

Os LGrdG de Água Azul do Norte (Figura 4) são, neste estudo, comparados à Suíte Guarantã (Almeida et al., 2010). Mineralógica e petrograficamente, os LGrdG são similares às rochas da Suíte Guarantã. Apresentam textura grossa e coloração esbranquiçada a rosada, com pórfiros subidiomórficos de plagioclásio e álcali feldspato rosado. A biotita é a única fase ferromagnesiana, e o epidoto magmático ocorre comumente associado a ela. O conteúdo de minerais máficos é $<7 \%$, enquanto nos leucogranodioritos e granitos da Suíte Guarantã é $\leq 10 \%$. Geoquimicamente, os LGrdG são pobres em $\mathrm{MgO}, \mathrm{TiO}_{2}, \mathrm{CaO}, \mathrm{P}_{2} \mathrm{O}_{5}, \mathrm{FeO}_{\mathrm{t}} \mathrm{e}$ $\mathrm{K}_{2} \mathrm{O}$ e enriquecidos em $\mathrm{Al}_{2} \mathrm{O}_{3}$ e $\mathrm{Na}_{2} \mathrm{O}$, superpondo-se ou aproximando-se do campo definido para as rochas da Suíte Guarantã (Figura 6). Em termos de elementos-traço, mostram empobrecimento em Rb, Y, La, Ce, Ni, \#Mg, Rb/Sr, Sr/Ba e teores moderados de $\mathrm{Ba}$ e Sr, incidindo dominantemente no campo das rochas da Suíte Guarantã (Figuras 7e 8). Embora os LGrdG da área de estudo sejam mais empobrecidos em ETR (exceto a amostra MC-94) quando comparados às rochas da Suíte Guarantã (Figura 9B), os padrões de fracionamento são similares, com diferenças mais evidentes nas anomalias de Eu (Eu/Eu* em LGrdG = 0,59-1,46; Suíte Guarantã = 0,73-0,98, com uma amostra apresentando valor de 1,21; Almeida et al., 2011). Com relação às séries magmáticas, os LGrdG deste estudo e as rochas da Suíte Guarantã mostram caráter fracamente peraluminoso (Figura 10A) e assinatura cálcio-alcalina característica, com os LGrdG incidindo nos campos das rochas com baixo a médio-K, enquanto as rochas da Suíte Guarantã distribuem-se nos campos de médio-Ka shoshonítico no diagrama $\mathrm{K}_{2} \mathrm{O}$ versus $\mathrm{SiO}_{2}$ (Figuras 10C-10D). No diagramaAn-Ab-Or, as rochas LGrdG ocupam dominantemente o campo trondhjemítico, e as rochas da Suíte Guarantã distribuem-se nos campos trondhjemítico e granítico daquele diagrama (Figura 10B).

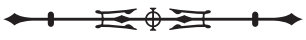


Biotita-epidoto-trondhjemito versus Trondhjemitos e Tonalitos do TGGRM

A associação trondhjemítica que ocorre nas porções leste e sudeste da área de estudo (Figura 4) é comparada geoquimicamente aos trondhjemitos Mogno e Água Fria e aos tonalitos Arco Verde, Caracol e Mariazinha, aflorantes no TGGRM. Os BEpTrd mostram maior afinidade em termos de $\mathrm{CaO}, \mathrm{Al}_{2} \mathrm{O}_{3}, \mathrm{MgO}, \mathrm{Na}_{2} \mathrm{O}$ com as rochas do Trondhjemito Mogno e dos tonalitos Mariazinha e Arco Verde (Figuras 11A-11D). Em termos de Rb, Ba e Zr, mostram superposição com as rochas dos trondhjemitos Mogno e Água Fria e as do Tonalito Mariazinha (Figuras 11E-11G). Com relação aos padrões de ETR (Figura 12), os BEpTrd se superpõem às rochas dos TTG do Domínio Rio Maria, porém mostram maior similaridade com o padrão definido pelas rochas do Trondhjemito Mogno, tanto em termos de elementos terras raras leves quanto pesadas, e do Trondhjemito Água Fria, embora estas últimas apresentem conteúdos mais baixos de ETRL (Figura 12G). Outras características geoquímicas que permitem correlacionar os BEpTrd com o Trondhjemito Mogno são suas altas razões La/Yb, Sr/Y e Nb/Ta (Figura 13), as quais seriam indicativas de magmas gerados a pressões $>1,5$ Gpa (Moyen \& Stevens, 2006; Moyen, 2009). Por outro lado, nas rochas do Trondhjemito Água Fria, tais razões são intermediárias e indicariam pressões comparativamente inferiores, entre 1,5-1,0 Gpa. Rochas granitoides com padrão de ETR fortemente fracionado, empobrecidas em ETRP e Y e enriquecidas em Sr, Eu e, na razão Sr/Y, similar ao Trondhjemito Mogno e ao BEpTrd deste estudo, seriam indicativas de fusões geradas na presença de granada e anfibólio ou teriam sua evolução magmática controlada pelo fracionamento de anfibólio e granada (Moyen \& Stevens, 2006; Moyen, 2009; Almeida et al., 2011).

\section{CONCLUSÕES}

Quatro tipos principais de rochas granitoides arqueanas foram identificadas entre as cidades de Água Azul do Norte e Ourilândia do Norte (Figura 4): 1) anfibólio-biotita- granodioritos (ABGrd) fortemente saussuritizados, aflorantes a norte, nordeste e a sul de Ourilândia do Norte, com idade de cristalização de $2875 \pm 2$ Ma e correlacionados, em termos petrográicos, geoquímicos e geocronológicos, à Suíte Sanukitoide Rio Maria; 2) biotita-granodioritos (BGrd) pouco alterados, situados a norte-noroeste de Água Azul do Norte, com idade de cristalização de $2884 \pm 3$ Ma, petrográfica e geoquimicamente distintos dos $\mathrm{ABG}$ rd e dos sanukitoides Rio Maria, tratando-se, provavelmente, de uma unidade geológica ainda sem denominação; 3) leucogranodioritosgranitos (LGrdG) aflorantes imediatamente a sul de Água Azul do Norte e correlacionados às rochas da Suíte Guarantã; 4) biotita-epidoto-trondhjemitos (BEpTrd), ocorrendo a sul-sudoeste de Água Azul do Norte e apresentando fortes similaridades petrográficas e geoquímicas com as rochas do Trondhjemito Mogno.

O estudo comparativo envolvendo geologia, petrografia, geoquímica e, em parte, geocronologia entre as unidades estudadas e suas correlatas do TGGRM permitiu um posicionamento estratigráfico mais conclusivo das rochas arqueanas situadas entre as cidades de Água Azul do Norte e Ourilândia do Norte, porção sudeste do Cráton Amazônico. Tal fato demonstra que as rochas granitoides arqueanas dominantes no TGGRM estendemse também até a porção noroeste desse domínio.

\section{AGRADECIMENTOS}

Ao Instituto de Geociências da Universidade Federal do Pará (IG-UFPA), pelo suporte técnico e laboratorial; à Coordenação de Aperfeiçoamento de Pessoal de Nível Superior (CAPES), pela concessão de bolsa de mestrado ao primeiro autor; aos pesquisadores e alunos do Grupo de Pesquisa Petrologia de Granitoides (GPPG), pelo apoio nas diversas etapas deste trabalho. Este artigo é uma contribuição para o Instituto Nacional de Ciência e Tecnologia (INCT) de Geociências da Amazônia (Conselho Nacional de Desenvolvimento Científico e Tecnológico/Ministério da Ciência e Tecnologia/Fundação Amazônia Paraense de Amparo à Pesquisa - CNPq/MCT/ FAPESPA - Processo no 573733/2008-2). 


\section{REFERÊNCIAS}

ALMEIDA, J. A. C., M. A. OliVEIRA, R. DALL'AGNOL, F. J. ALTHOFF \& R. M. K. BORGES, 2008. Relatório de mapeamento geológico na escala 1:100.000 da Folha Marajoara (SB-22-Z-C-V): 1-147. Serviço Geológico do Brasil - CPRM.

ALMEIDA, J. A. C., R. DALL'AGNOL, S. B. DIAS \& F. J. ALTHOFF, 2010. Origin of the Archean leucogranodiorite-granite suites: Evidence from the Rio Maria terrane and implications for granite magmatism in the Archean. Lithos 120(3-4): 235-257.

ALMEIDA, J. A. C., R. DALL'AGNOL, M. A. OLIVEIRA, M. J. B. MACAMBIRA, M. M. PIMENTEL, O. T. RÄMÖ, F. V. GUIMARÃES \& A. A. S. LEITE, 2011. Zircon geochronology, geochemistry and origin of the TTG suites of the Rio Maria granite-greenstone terrane: Implications for growth of Archean crust of the Carajás province, Brazil. Precambrian Research 187(1-2): 201-221.

ALMEIDA, J. A. C., R. DALL'AGNOL \& A. A. S. LEITE, 2013. Geochemistry and zircon geochronology of the Archean granite suites of the Rio Maria granite-greenstone terrane, Carajás Province, Brazil. Journal of South American Earth Sciences 42: 103-126.

ALTHOFF, F. J., P. BARBEY \& A.-M. BOULLIER, 2000. 2.8-3.0 Ga plutonism and deformation in the SE Amazonian craton: the Archean granitoids of Marajoara (Carajás Mineral province, Brazil). Precambrian Research 104(3-4): 187-206.

BARKER, F., 1979. Trondhjemites: definition, environment and hypotheses of origin. In: F. BARKER (Ed.): Trondhjemites, dacites and related rocks: 1-12. Elsevier, Amsterdam.

BARKER, F. \&J. G. ARTH, 1976. Generation of trondhjemitic-tonalitic liquids and Archaean bimodal trondhjemite-basalt suites. Geology 4(10): 596-600.

BICKLE, M. J., L. F. BETTENAY, H. J. CHAPMAN, D. I. GROVES, N. J. MCNAUGHTON, I. H. CAMPBELL \& J. R. DE LAETER, 1993. Origin of the 3500-3300 Ma calc-alkaline rocks in the Pilbara Archaean: isotopic and geochemical constraints from the Shaw Batholith. Precambrian Research 60(1-4): 117-149.

BRITO NEVES, B. B. \& U. G. CORDANI, 1991. Tectonic evolution of South America during the Late Proterozoic. Precambrian Research 53(1-2): 23-40.

BOWDEN, P., R. A. BATCHELOR, B. W. CHAPPELL, J. DIDIER \& J. LAMEYRE, 1984. Petrological, geochemical and source criteria for the classification of granitic rocks: a discussion. Physics of the Earth and Planetary Interiors 35(1-3): 1-11.

CHAMPION, D. C. \& R. H. SMITHIES, 2007. Geochemistry of Paleoarchean Granites of the East Pilbara Terrane, Pilbara Craton, Western Australia: implications for early Archean crustal growth. In: M. J. VAN KRANENDONK, R. H. SMITHIES \& V. C. BENNETT (Eds.): Earth's oldest rocks: 369-410. Elsevier (Developments in Precambrian Geology, 15), Amsterdam.
CONDIE, K. C., 1993. Chemical composition and evolution of the upper continental crust: contrasting results from surface samples and shales. Chemical Geology 104(1-4): 1-37.

DALL'AGNOL, R., Z. S. SOUZA, F. J. ALTHOFF, C. E. M. BARROS, A. A. S. LEITE \&X. S. JORGEJOÃO, 1997. General aspects of the granitogenesis of the Carajás metallogenic province. Extended Abstracts of the International Symposium on Granites and Associated Mineralizations 2: 135-161.

DALL'AGNOL, R., O. T. RÄMÖ, M. S. MAGALHÃES \& M. J. B. MACAMBIRA, 1999. Petrology of the anorogenic oxidised Jamon and Musa granites, Amazonian Craton: implications for the Genesis of Proterozoic A-type granites. Lithos 46(3): 431-462.

DALL'AGNOL, R., N. P. TEIXEIRA, O. T. RÄMÖ, C. A. V. MOURA, M. J. B. MACAMBIRA \& D. C. OLIVEIRA, 2005. Petrogenesis of the Paleoproterozoic, rapakivi, A-type granites of the Archean Carajás metallogenic province, Brazil. Lithos 80: 101-129.

DALL'AGNOL, R., M. A. OLIVEIRA, J. A. C. ALMEIDA, F. J. ALTHOFF, A. A. S. LEITE, D. C. OLIVEIRA \& C. E. M. BARROS, 2006. Archean and Paleoproterozoic granitoids of the Carajás metallogenetic province, eastern Amazonian Craton. Symposium on Magmatism, Crustal Evolution, and Metallogenesis of the Amazonian Craton 1: 97-150.

GUIMARÃES, F. V., R. DALL'AGNOL, J. A. C. ALMEIDA \& M. A. OLIVEIRA, 2010. Caracterização geológica, petrográfica e geoquímica do Trondhjemito Mogno e Tonalito Mariazinha, Terreno GranitoGreenstone mesoarqueano de Rio Maria, SE do Pará. Revista Brasileira de Geociências 40(2): 196-211.

HANSON, G. N., 1978. The application of trace elements to the petrogenesis of igneous rocks of granitic composition. Earth and Planetary Science Letters 38(1): 26-43.

IRVINE, T. N. \& W. R. A. BARAGAR, 1971. A guide to the chemical classification of the common volcanic rocks. Canadian Journal of Earth Sciences 8(5): 523-548.

KOBER, B., 1986 Whole-grain evaporation for ${ }^{207} \mathrm{~Pb} /{ }^{206} \mathrm{~Pb}$-ageinvestigations on single zircons using a double-filament thermal ion source. Contributions to Mineralogy and Petrology 93(4): 482-490.

KRÖNER, A., E. HEGNER, J. I. WENDT \& G. R. BYERLY, 1996. The oldest part of the Barberton granitoid-greenstone terrain, South Africa: evidence for crust formation between 3.5 and $3.7 \mathrm{Ga}$. Precambrian Research 78(1-3): 105-124.

LAFON, J. M., E. RODRIGUES \& K. D. DUARTE, 1994. Le granite Mata Surrão: un magmatisme monzogranitique contemporain des associations tonalitiques-trondhjemitiques-granodioritiques archéennes de la région de Rio Maria (Amazonie Orientale, Brésil). Comptes Rendus de l'Académie des Sciences. Serie 2. Sciences de la terre et des planètes 318(5): 643-649.

LAMEYRE, J. \& P. BOWDEN, 1982. Plutonic rock type series: discrimination of various granitoid series and related rocks. Journal of Volcanology and Geothermal Research 14(1-2): 169-186.

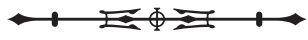


LEITE, A. A. S., R. DALL'AGNOL \& F. J. ALTHOFF, 1999. Geoquímica e aspectos petrogenéticos do Granito Xinguara, Terreno GranitoGreenstone de Rio Maria - Cráton Amazônico. Revista Brasileira de Geociências 23(3): 429-436.

LEITE, A. A. S., R. DALL'AGNOL, M. J. B. MACAMBIRA \& F. J. ALTHOFF, 2004. Geologia e geocronologia dos granitoides arqueanos da região de Xinguara-PA e suas implicações na evolução do terreno granito-greenstone de Rio Maria, Cráton Amazônico. Revista Brasileira de Geociências 34(4): 447-458.

MACAMBIRA, M. J. B. \&J. M. LAFON, 1995. Geocronologia da Província Mineral de Carajás: síntese dos dados e novos desafios. Boletim do Museu Paraense Emílio Goeldi, série Ciências da Terra 7: 263-288.

MACAMBIRA, M. J. B. \& J. LANCELOT, 1996. Time constraints for the formation of the Archean Rio Maria crust, Southeastern Amazonian Craton, Brazil. International Geology Review 38(12): $1134-1142$.

MACAMBIRA, M. J. B., J. B. S. COSTA, F. J. ALTHOFF, J. M. LAFON, J. C. V. MELO \& A. SANTOS, 2000. New geochronological data for the Rio Maria TTG terrane: implications for the time constraints of the crustal formation of the Carajas Province, Brazil. Abstracts of International Geological Congress 31: $1 \mathrm{CD}-\mathrm{ROM}$.

MARTIN, H., 1987. Petrogenesis of Archaean trondhjemites, tonalites and granodiorites from eastern Finland: major and trace element geochemistry. Journal of Petrology 28(5): 921-953.

MARTIN, H., 1994. The Archean grey gneisses and the gneisses of continental crust. In: K. C. CONDIE (Ed.): Archean crustal evolution: 205-259. Elsevier (Developments in Precambrian Geology, 11), Amsterdam.

MARTIN, H., J. J. PEUCAT, P. SABATÉ \& J. C. CUNHA, 1997. Crustal evolution in the early Archaean of South America: example of the Sete Voltas Massif, Bahia State, Brazil. Precambrian Research 82(1-2): 35-62

MOYEN, J. F., 2009. High Sr/Y and La/Y ratios: the meaning of the "adakitic signature". Lithos 112(3-4): 556-574.

MOYEN, J. F. \& G. STEVENS, 2006. Experimental constraints on TTG petrogenesis: implications for Archean geodynamics. In: K. BENN, J.-C. MARESCHAL \& K. C. CONDIE (Eds.): Archean geodynamics and environments: 149-178. American Geophysical Union, Washington.

MOYEN, J. F., G. STEVENS, A. F. M. KISTERS \& R. W. BELCHER, 2007. TTG plutons of the Barberton granitoid-greenstone terrain, South Africa. In: M. J. VAN KRANENDONK, R. H. SMITHIES \& V. C. BENNET (Eds.): Earth's oldest rocks: 607-668. Elsevier (Developments in Precambrian Geology, 15), Amsterdam.

NAKAMURA, N., 1974. Determination of REE, Ba, Fe, Mg, Na and $\mathrm{K}$ in carbonaceous and ordinary chondrites. Geochimica et Cosmochimica Acta 38(5): 757-775.
O'CONNOR, J. T., 1965. A classification for quartz-rich igneous rocks based on feldspar ratios. United States Geological Survey Professional Paper 525B: 79-84.

OLIVEIRA, D. C., R. DALL'AGNOL, C. E. M. BARROS \& M. A. OLIVEIRA, 2009. Geology, geochemistry and magmatic evolution of the paleoproterozoic, anorogenic oxidized A-type Redenção granite of the Jamon suite, Eastern Amazonian Craton, Brazil. The Canadian Mineralogist 47: 1441-1468.

OLIVEIRA, D. C., S. P. NEVES, R. I. F. TRINDADE, R. DALL'AGNOL, G. MARIANO \& P. B. CORREIA, 2010. Magnetic anisotropy of the Redenção granite, eastern Amazonian craton: implications for the emplacement of A-type plutons. Tectonophysics 493(1-2): 27-41.

OLIVEIRA, M. A., R. DALL'AGNOL \& F. J. ALTHOFF, 2006. Petrografia e Geoquímica do Granodiorito Rio Maria da região de Bannach e comparações com as demais ocorrências no terreno GranitoGreenstone de Rio Maria - Pará. Revista Brasileira de Geociências 36(2): 313-326.

OLIVEIRA, M. A., R. DALL'AGNOL, F. J. ALTHOFF \& A. A. S. LEITE, 2009. Mesoarchean sanukitoid rocks of the Rio Maria GraniteGreenstone Terrane, Amazonian craton, Brazil. Journal of South American Earth Sciences 27(2-3): 146-160.

PAIVA JÚNIOR, A. L., C. N. LAMARÃO \& P. H. A. LIMA, 2011. Geologia, petrografia e geoquímica do batólito Seringa, Província Carajás, SSE do Pará. Revista Brasileira de Geociências 41(2): 185-202.

PECCERILLO, A. \& S. R. TAYLOR, 1976. Geochemistry of eocene calc-alkaline volcanic rocks from the Kastamonu area, Northern Turkey. Contributions to Mineralogy and Petrology 58(1): 63-81.

PIMENTEL, M. M. \& N. MACHADO, 1994. Geocronologia U-Pb dos terrenos granito-greenstone de Rio Maria, Pará. Boletim de Resumos Expandidos do Congresso Brasileiro de Geologia 38(2): 390-391.

ROLANDO, A. P. \& M. J. B. MACAMBIRA, 2003. Archean crust formation in Inajá range area, SSE of Amazonian Craton, Brazil, basead on zircon ages and $\mathrm{Nd}$ isotopes. Expanded Abstracts of the South American Symposium on Isotope Geology 4: 1 CD-ROM.

SANTOS, J. O. S., 2003. Geotectônica do Escudo das Guianas e BrasilCentral. In: L. A. BIZZI, C. SCHOBBENHAUS, R. M. VIDOTTI \& J. H. GONÇALVES (Eds.): Geologia, tectônica e recursos minerais do Brasil: 169-226. Serviço Geológico do Brasil, Brasília.

SANTOS, J. O. S., L. A. HARTMANN, H. E. GAUDETTE, D. I. GROVES, N. J. MCNAUGHTON \& I. R. FLETCHER, 2000. A new understanding of the provinces of the Amazon craton based on integration of field and $\mathrm{U}-\mathrm{Pb}$ and $\mathrm{Sm}-\mathrm{Nd}$ geochronology. Gondwana Research 3(4): 453-488.

SHAND, S. J., 1950. Eruptive rocks, their genesis, composition, classification and their relation to ore-deposits: 1-488. Thomas Murby, London.

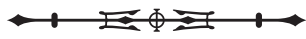


SIMPSON, C. \&. R. P. WINTSCH, 1989. Evidence for deformationinduced K-feldspar replacement by myrmekite. Journal of Metamorphic Geology 7(2): 261-275.

SMITH, J. V., 1974. Feldspar minerals: crystal structures, physical, chemical and microtextural properties: 1-627. Springer-Verlag, New York.

SOUZA, Z. S., A. POTREL, J. M. LAFON, F. J. ALTHOFF, M. M. PIMENTEL, R. DALL'AGNOL \& C. G. OLIVEIRA, 2001. Nd, Pb and $\mathrm{Sr}$ isotopes in the Identidade Belt, an Archaean greenstone belt of the Rio Maria region (Carajás Province, Brazil): implications for the Archaean geodynamic evolution of the Amazonian Craton. Precambrian Research 109(3-4): 293-315.

STRECKEISEN, A., 1976. To each plutonic rock its proper name. Earth-Science Reviews 12(1): 1-33.

TASSINARI, C. C. G. \& M. J. B. MACAMBIRA, 1999. Geochronological provinces of the Amazonian Craton. Episodes 22(3): 174-182.
TASSINARI, C. C. G. \& M. J. B. MACAMBIRA, 2004. A evolução tectônica do Cráton Amazônico. In: V. MANTESSO NETO, A. BARTORELLI, C. D. R. CARNEIRO \& B. B. BRITO-NEVES (Orgs.): Geologia do continente Sul-Americano: evolução da obra de Fernando Flávio Marques de Almeida: 471-486. BECA, São Paulo.

VASQUEZ, M. L., L. T. ROSA-COSTA, C. G. SILVA, P. F. RICCI, J. O. BARBOSA, E. L. KLEIN, E. S. LOPES, E. B. MACAMBIRA, C. L. CHAVES, J. M. CARVALHO, J. G. OLIVEIRA, G. C. ANJOS \& H. R. SILVA, 2008. Geologia e recursos minerais do estado do Pará: Sistema de Informações Geográficas - SIG: texto explicativo dos mapas geológico e tectônico e de recursos minerais do estado do Pará. In: M. L. VASQUEZ \& L. T. ROSA-COSTA (Orgs.): Escala 1:1.000.000: 118-121. CPRM, Belém.

VERNON, R. H., 2004. A practical guide to Rock Microstructure: 1-594. Cambridge University Press, United Kingdom.

WEDEPOHL, K. H., 1970. Rubidium. In: K. H. WEDEPOHL (Ed.): Handbook of geochemistry: 37B-37N. Springer-Verlag, New York. 